\title{
Applications of metal and non-metal catalysts for the synthesis of oxygen containing five-membered polyheterocylces: a mini review
}

\author{
Navjeet Kaur ${ }^{1} \cdot$ Meenu Devi $^{1} \cdot$ Yamini Verma ${ }^{1}$ - Pooja Grewal ${ }^{1}$. Pranshu Bhardwaj ${ }^{1}$. Neha Ahlawat ${ }^{1}$. \\ Nirmala Kumari Jangid ${ }^{1}$
}

(c) Springer Nature Switzerland AG 2019

\begin{abstract}
The investigation of methods for the chemical synthesis is a growing area of interest due to increasing environmental issues. The use of catalysts in organic reactions has gained extensive interest. Metal and non-metal catalysts provided a new improved alternative to traditional methods in modern synthetic chemistry. The aim of present review is to focus on the applications of metals and non-metals for the synthesis of oxygen containing five-membered polyheterocylces.
\end{abstract}

Keywords Catalysis $\cdot$ Heterocycles $\cdot$ Oxygen

\section{Introduction}

The heterocyclic compounds are used in chemical, biological, and industrial fields [1-18]. Heterocyclic compounds form the central core of many biologically active natural products and pharmaceutical agents (such anti-viral, anti-inflammatory, anti-bacterial, anti-tumoral, and antioxidant activities agents), and are used in herbicides and corrosion inhibitors. Heterocyclic compounds due to their presence in natural products and biologically active compounds are the most explored compounds [19-51]. They are significant not only for the synthesis of drugs, pharmaceuticals, and pigments, but also for the development of organic functional materials. Many biologically active pharmaceuticals, agrochemicals, modifiers, and additives used in industrial applications like plastics, cosmetics reprography, and information storage are heterocycles in nature [52-73].

Many protocols have been investigated for the synthesis of heterocycles. These protocols for the formation of heterocyclic compounds involve carbon-nitrogen bondforming reactions such as nucleophilic substitution, reductive amination, or dipolar cycloaddition for ring closure [74-87]. Although various protocols have been developed, their functional group tolerance and substrate scope is often limited. In recent years, for the synthesis of heterocycles many new protocols have been developed which involved metal and non-metal assisted carbon-nitrogen bond-forming reactions. These reactions tolerated a number of functional groups, occur under mild conditions, and proceed with high stereoselectivity. The utilization of metal and non-metal allows highly convergent multicomponent coupling approaches, which form many bonds and/or stereocenters in one-pot protocol [88-90].

Ongoing my interest in the synthesis of five-membered $O$-heterocycles using silver [66] and the synthesis of seven and higher-membered $O$-heterocycles using metal and non-metal [67], in this further review we end our overview with the description five-membered $O$-polyheterocyclic compounds. This review article describes the approaches for the preparation of various five-membered polyheterocyclic compounds with oxygen heteroatom through metal and non-metal assisted reactions. The synthesis of different heterocycles is classified into different categories based on the type of metal and non-metal used.

\footnotetext{
Navjeet Kaur, nvjithaans@gmail.com | Department of Chemistry, Banasthali Vidyapith, Banasthali, Rajasthan 304022, India.
} 


\section{Metal and non-metal assisted synthesis of five-membered $\mathbf{O}$-polyheterocycles}

\subsection{Aluminium assisted synthesis}

The phenols and phenacyl bromide were reacted via $\mathrm{O}$-alkylation, $\mathrm{C}-\mathrm{C}$ coupling/cyclization, and dehydration olefination tandem reactions for one-pot synthesis of functionalized benzofurans. The reactions were performed in the presence of alumina supported inorganic bases under solvent-free and microwave irradiation conditions. Ethers were formed as by-products (Scheme 1) [38, 91, 92].

Benzofurans are present in various natural products and possess biological activity and therefore have attracted considerable interest [92-95]. The 2-aroylbenzo[b]furans were synthesized easily in excellent yields (up to 96\%) from $a$-tosyloxyketones and salicylaldehydes in the presence of potassium fluoride-aluminium oxide (Scheme 2) $[96,97]$. The 2 -aroylbenzo[b]furans were prepared under solvent-less conditions from readily available tosyloxyketones and mineral oxides in reactions that were accelerated under MWs.

\subsection{Bismuth assisted synthesis}

The 3-allylphthalide was formed in high yields by Barbiertype reaction of allyl bromide and phthalaldehydic acid with bismuth chloride/magnesium [98] or bismuth chloride/zinc [99] (Scheme 3) [100]. Various pharmaceutically interesting phthalides are found, for example in plants from the Apiaceae family [101].

\subsection{Cesium assisted synthesis}

Ugi four-component reaction is one of the powerful routes to access structural complexity [102]. Moreover, the Ugi four-component reaction adducts were converted into several cyclic scaffolds via post-Ugi conversions which allowed a facile access to various biologically relevant heterocyclic compounds. Among them, benzofuran structural functionality is present in many pharmacologically active natural products. The benzofurans were synthesized via Rap-Stoermer reaction of the linear dipeptide-like Ugi-4CR adducts under microwaves [103]. The aniline was reacted with salicyaldehydes in the presence of cesium carbonate

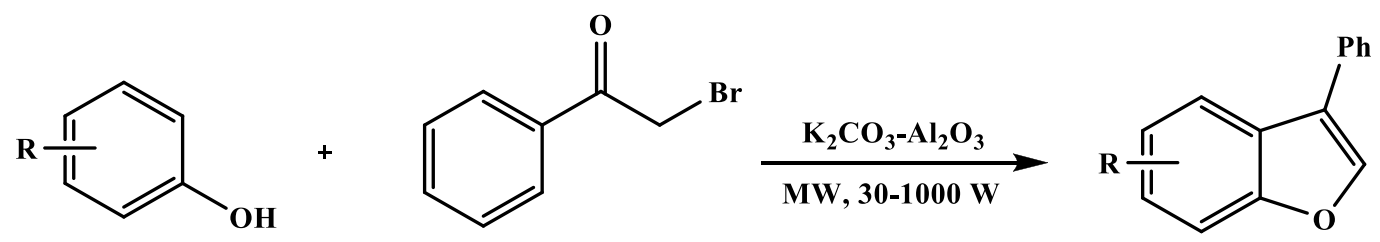

Scheme 1 Synthesis of 3-phenylbenzofuran<smiles>[R]c1ccc(C(=O)O[GaH])cc1</smiles>

Scheme 2 Synthesis of 2-aroylbenzo[b]furans

Scheme 3 Synthesis of 3-allylisobenzofuran-1(3H)-one<smiles>O=Cc1ccccc1C(=O)O</smiles>

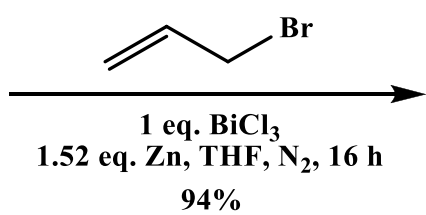

$94 \%$<smiles>C=CCC1OC(=O)c2ccccc21</smiles> 
under controlled microwave heating in acetonitrile for 15-30 min at $80-140^{\circ} \mathrm{C}$ to directly provide benzofurans in $43-90 \%$ yields. With benzofurans in hand, two different heterocyclic compounds (2-oxindoles and 5,6-dihydrophenanthridines) were easily prepared by intramolecular direct arylation and intramolecular $\mathrm{N}$-arylation processes in the presence of Pd catalyst (Scheme 4) [38, 104-107].

\subsection{Chromium assisted synthesis}

The carbonyl-ene-yne was reacted with styrene in catalytic amount of $\mathrm{Cr}(\mathrm{CO})_{5}$ (THF) to produce (2-furyl)cyclopropane in $85 \%$ yield [108]. Complexes of late transition metals, like rhodium, ruthenium, palladium, irridium, and platinum, also catalyzed the cyclopropanation involving (2-furyl) carbene intermediates. The highest catalytic activity was shown by complex rhodium acetate in the cyclopropanation reaction. Electron-rich alkenes like ketene diethyl acetal and tert-butyl vinyl ether acted as good acceptors of carbene intermediates to afford the excellent yields of cyclopropanated products. The complex rhodium acetate served as an effective catalyst for cyclopropanation with an alkyl ketone to afford the cyclopropanated product in lower yield under other transition metal catalysis. Miki and co-workers synthesized (2-furyl)-cyclopropanes by transition-metal-catalyzed cyclopropanation of alkenes with 1-benzoyl cis-1-en-3-yne (Scheme 5) [109, 110]. Many transition-metal complexes, like $\mathrm{Mo}(\mathrm{CO})_{5}(\mathrm{THF}), \mathrm{Cr}(\mathrm{CO})_{5}(\mathrm{THF})$, $\left[\mathrm{RuCl}_{2}(\mathrm{CO})_{3}\right]_{2}, \mathrm{~W}(\mathrm{CO})_{5}(\mathrm{THF})$, palladium chloride, $[\mathrm{RhCl}-$ (cod) $]_{2}$, and platinum chloride, acted as catalysts for this transformation [78-87, 111].

\subsection{Gold assisted synthesis}

He and co-workers [112] synthesized benzofurans from aryl allyl ethers via $\mathrm{Ph}_{3}$ PAuOTf-catalyzed Claisen rearrangement. This was followed by a tandem phenol addition (Scheme 6) $[113,114]$.

Pale et al. [115] reported a reaction of unactivated $\omega$-acetylenic acids for the construction of different<smiles>[R4]NC(=O)C(c1ccccc1Br)N(C(=O)CBr)c1ccc([R])cc1</smiles>

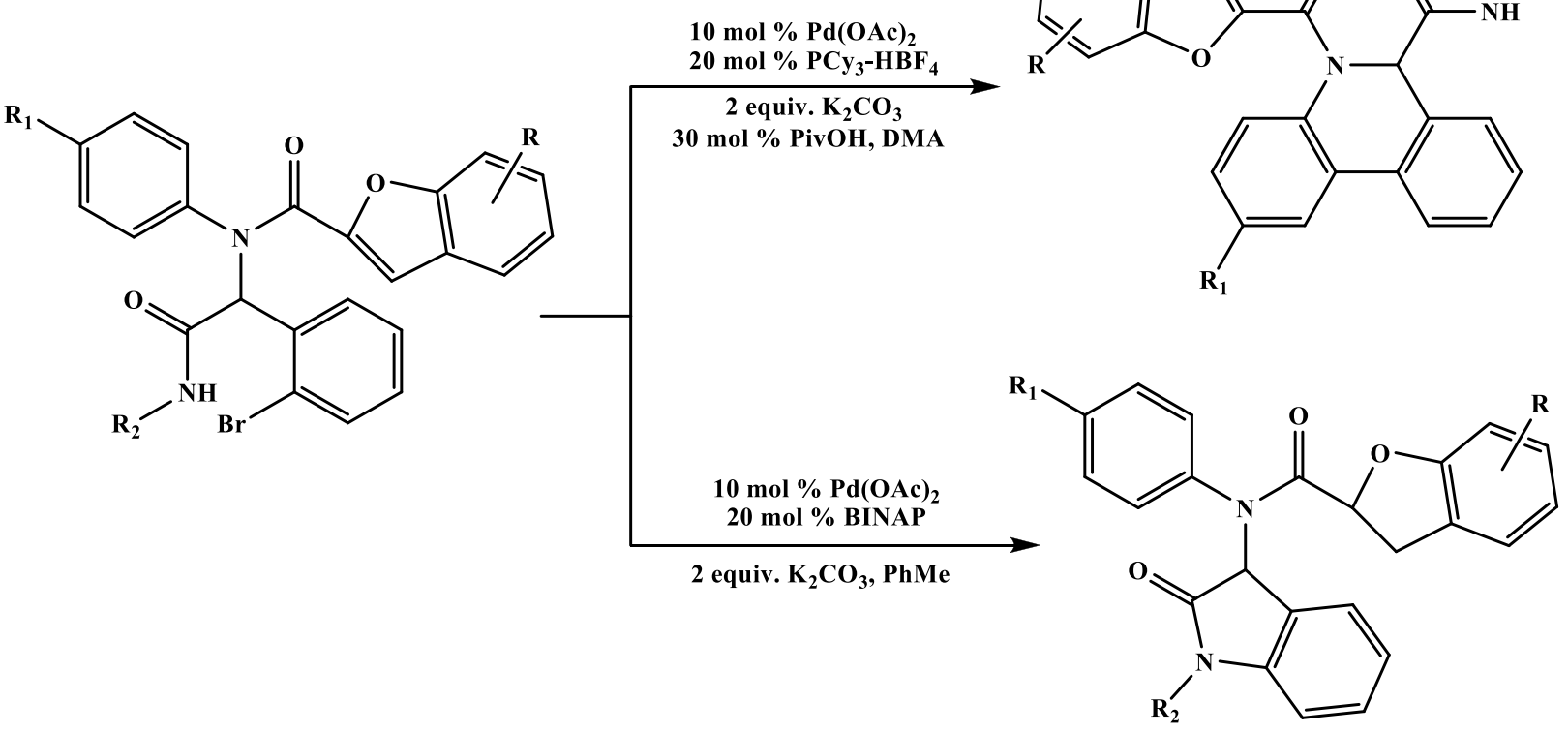

Scheme 4 Synthesis of benzofurans 


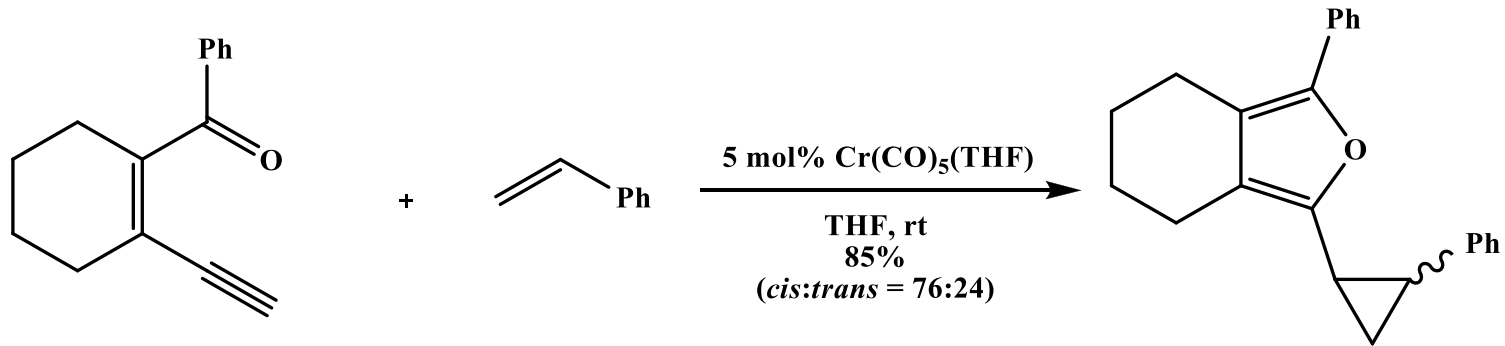

Scheme 5 Synthesis of (2-furyl)cyclopropane

Scheme 6 Synthesis of 2-methyl-2,3-dihydrobenzofuran<smiles>C=CCOc1ccccc1</smiles><smiles>CC1Cc2ccccc2O1</smiles><smiles>CC#Cc1ccccc1CC(=O)O</smiles>

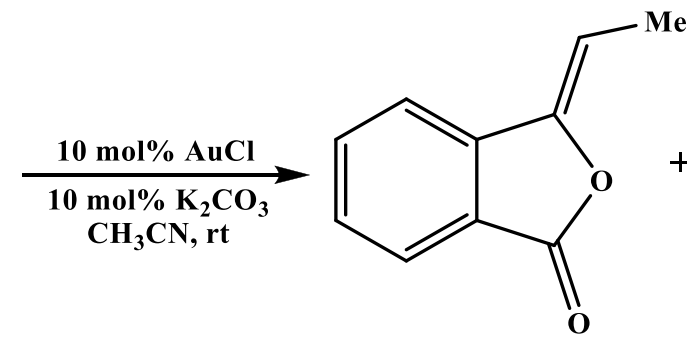

Me<smiles>[X]c1cc2ccccc2c(=O)o1</smiles>

Scheme 7 Synthesis of (Z)-3-ethylideneisobenzofuran-1(3H)-one and 3-methyl-1H-isochromen-1-one<smiles>C#CCOCc1ccco1</smiles>

Scheme 8 Synthesis of 1,3-dihydroisobenzofuran-5-ol and 1,3-dihydroisobenzofuran-4-ol

ring-sized lactones. A straightforward trick was applied to boost the nucleophilicity of carboxylic group: a catalytic amount of potassium carbonate to produce the carboxylate anion. The limitations and regioselectivity of the reaction was examined by choosing gold(I) chloride catalyzed cycloisomerization of $\gamma$ - and $\delta$-acetylenic acids [116]. Both the exo- and endo-derivatives were obtained by intramolecular cyclization of $\gamma$ - or $\delta$-acetylenic acids. Uchiyama and co-workers [117] developed an acid-catalyzed regiocontrolled intramolecular 6-endo-dig cyclization of $\gamma$-acetylenic acids. On the other hand, the exo-dig cyclization occurred predominately in gold-catalyzed cycloisomerization reaction to provide the lactones as a single stereoisomer $Z$ and as the major products (Scheme 7) [118].

The phenols were synthesized by the reaction of 5-(2-furyl)-1-alkynes in the presence of $\mathrm{AuCl}_{3}$ catalyst (Scheme 8) $[119,120]$. The substrates such as 5-(2-furyl)1-alkynes substituted at $\mathrm{C}-5$ of the furan were cyclized to provide the phenols. The reaction occurred via an intramolecular [4+2] cycloaddition which was promoted by the $\eta^{2}$-coordination of gold(III) chloride to the alkyne [78-87, 121].

The tert-butyl(dimethyl)silyl protecting group was changed to a benzyl group which afforded high yields without loss in reactivity after using first time. The 
catalyst system was so stable that high reactivities and yields were reported even after air exposure for several days. The gold-catalyzed cycloisomerization with gold(III) bromide/[BMIM] $\left[\mathrm{PF}_{6}\right]$ system was also used for exocyclic $a$-hydroxyallene (Scheme 9). This substrate was difficult to cyclize and provided the expected bicyclic 2,5-dihydrofuran [122-124].

Before 2008, it was found that cationic [(NHC)Au] compounds catalyzed various "classical" enyne skeletal rearrangements [121, 125-131] which involved the synthesis of an auracarbene [132-141]. Recently, Zhang et al. [142] changed the olefin of an enyne with a carbonyl group and explored the benefit of reactivity of ynones with gold to produce interesting dipoles. This method allowed the synthesis of furan-fused polycyclic compounds (Scheme 10) [143].

Larock [144] and others [145] synthesized substituted furans from 2-(1-alkynyl)-2-alken-1-ones in the presence of transition metal catalyst [146-153]. The reaction occurred through the formation of an oxonium ion intermediate. During the development of a diversity-oriented tandem reactions for the preparation of heterocycles [154-161], authors reported a protocol for the construction of $3(2 \mathrm{H})$ furanones from 2-alkynyl-2-hydroxy carbonyl compounds, which occurred via cationic cyclization (Scheme 11). The electrophilicity for an intramolecular nucleophilic attack was enhanced upon the coordination of the triple bond of propargylic alcohol to a suitable transition-metal catalyst. The oxonium ion intermediate triggered an irreversible 1,2-shift analogous to a formal $a$-ketol rearrangement, [162-166] and subsequently protonation of the carbontransition-metal bond occurred to regenerate the catalyst and provide the $3(2 \mathrm{H})$-furanones. The primary amines were used in situ condensation step to expand the diversity of structures obtained from propargylic alcohol, and finally a 1,2-migration occurred to the adjacent iminium ion to afford 3-pyrrolones. The onium ion rearrangements were not utilized to terminate cationic cyclizations, while the related pinacol rearrangements were used to demonstrate the powerful protocol for designing cascade reactions [167-171].

This easy three step sequence was reported for the construction of aurone skeletons [172], natural flavonoids. Aurones possess many biological properties [173-177], and due to this many groups were interested in the development of convenient synthetic pathways [178-184]. The best results were reported with goldcatalyzed oxycyclization and have advantages such as excellent selectivities, milder reaction conditions, and avoided the formation of byproducts like flavones

Scheme 9 Synthesis of bicyclic 2,5-dihydrofuran<smiles>CC=C=C1CCCCC1O</smiles><smiles>CC1C=C2CCCCC2O1</smiles>

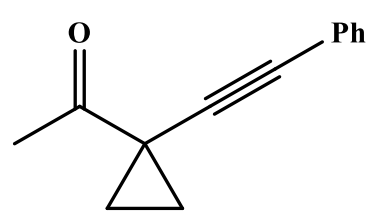<smiles>C=C(C)C</smiles>

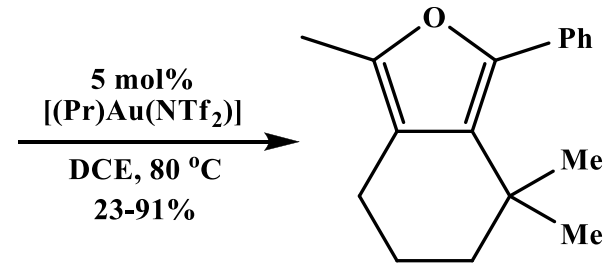

Scheme 10 Synthesis of 1,4,4-trimethyl-3-phenyl-4,5,6,7-tetrahydroisobenzofuran

Scheme 11 Synthesis of 4-methoxy-2-phenyl-4,5,6,7tetrahydrobenzofuran
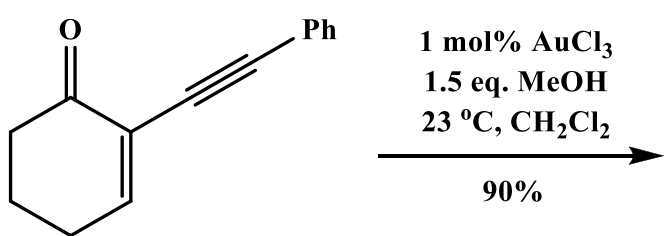<smiles>COC1CCCc2oc(-c3ccccc3)cc21</smiles>

SN Applied Sciences A SPRINGER NATURE journa 
(Scheme 12) [185]. In this case, complete regioselectivity and high yields were obtained [186].

The base-assisted domino nucleophilic addition/ annulation of simple ortho-alkynylbenzaldehydes was explored in-depth in the presence of alcohols (Scheme 13). Authors concentrated to rationalize the relationship between the nature of the cyclization mode and the substitution on the alkynyl terminus and on the selective preparation of the isobenzofuran framework $[187,188]$.

\subsection{Gold and silver assisted synthesis}

In carbonyl addition to alkynes, Hashmi and co-workers [189] used Boc-protected alkynylamines for similar cyclizations to afford oxazolinones, although the scope was limited to silyl-protected or terminal alkynes. Shin [190] noted that 3-O-Boc-1,5-enynes underwent highly diastereoselective cyclizations. $t$-Bu group acted as a leaving group, and this reaction led to highly substituted cyclohexene-fused carbonates (Scheme 14). An efficient tandem cyclization of tert-butyl carbonate derivatives of hex-1-en-5-yn-3-ol occurred in the presence of gold(I) catalyst where nucleophilic participation of the O-Boc

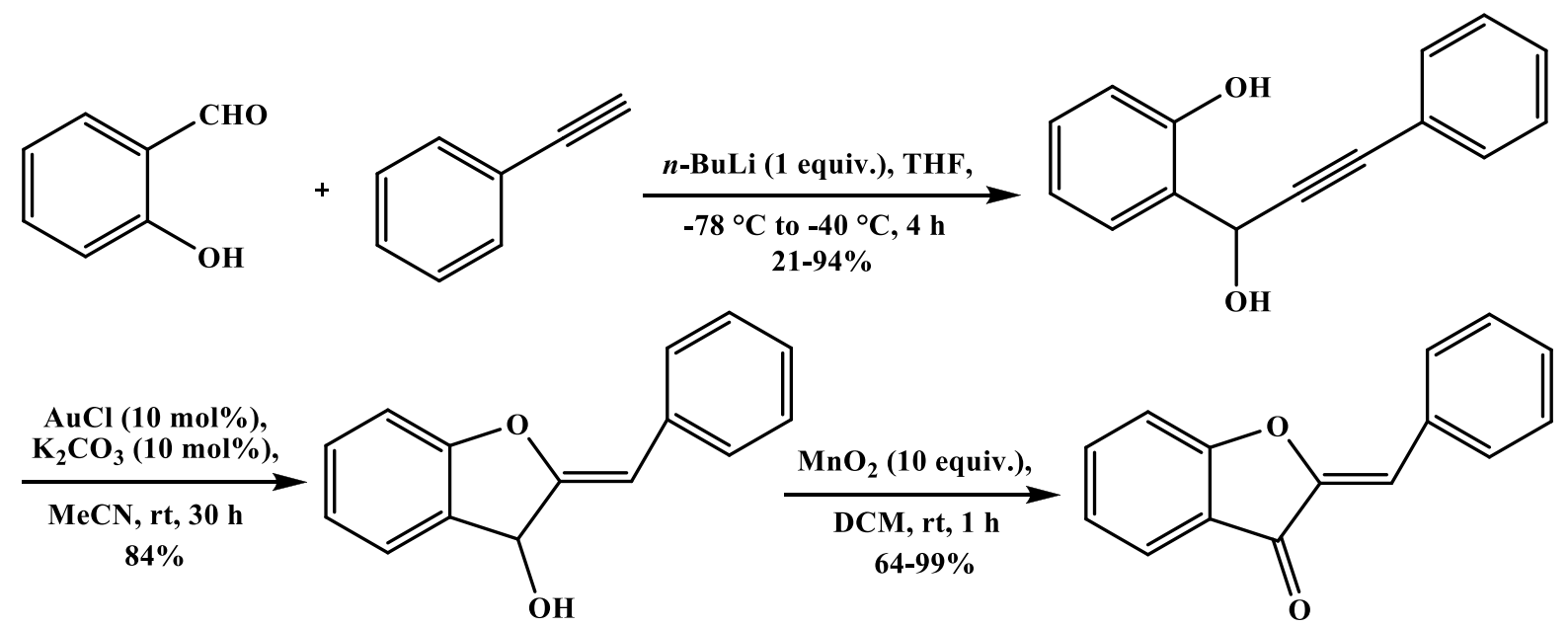

Scheme 12 Synthesis of (Z)-2-benzylidenebenzofuran-3(2H)-one<smiles>CC#Cc1ccccc1C=O</smiles>

Scheme 13 Synthesis of 1-methoxy-3-methyl-1H-isochromene and isobenzofuran

Scheme 14 Synthesis of (3aS,4R,7R,7aR)-3a,4,5,7tetramethyl-3a,4,7,7atetrahydrobenzo[d] $[1,3]$ dioxol-2-one<smiles>CC#C[C@H](C)[C@@H](OCC)C(C)=CC</smiles><smiles>CC1=C[C@H](C)[C@H]2OC(=O)O[C@]2(C)[C@H]1C(=O)O</smiles> 
group appeared to intercept a carbocationic (or cyclopropyl carbene) Au intermediate [191]. The reaction led to densely functionalized cyclohexene-3,4-diol derivatives where 1,2,3- or 1,2-stereocenters were controlled in a highly diastereoselective manner $[114,118]$.

The gold-catalyzed double intramolecular hydroalkoxylation was reported, for the construction of bis-benzannelated spiroketal core of natural bioactive rubromycins [192, 193], by Zhou et al. [194] (Scheme 15).

Wang and co-workers [195] synthesized polysubstituted C-vinyl butyrolactones via a gold-catalyzed highly diastereoselective cyclization of malonate substituted allylic acetates. The syn-4-acetoxycyclohexenyl malonate was treated with $\mathrm{AuPPh}_{3} \mathrm{Cl} / \mathrm{AgSbF}_{6}$ at $70^{\circ} \mathrm{C}$ in 1,2-dicholoethylene for $3 \mathrm{~h}$ for the synthesis of 3,4-anti4,5-syn-3-methoxycarbonyltetrahydrobenzobutyrolactone in $80 \%$ yield $[194,196,197]$ (Scheme 16$)$.

Liu and co-workers [198] synthesized 3-carbonylated benzofuran derivatives by $\mathrm{Au}(\mathrm{III})$-catalyzed tandem rearrangement/cyclization reaction of $\beta$-phenoxyimino ketone. The $\beta$-phenoxyimino ketone was prepared in situ from $O$-arylhydroxylamines and 1,3-dicarbonyl compounds (Scheme 17) [194].
Ketals are crucial targets and important key structures in organic synthesis [199-201]. Fused, bicyclic and spiroketals are recurring moieties in natural compounds, and their synthesis is a key step in many total preparations. Specially, spiroketals are present in various biomedically relevant non-natural and natural systems [202-205]. Many protocols were developed for the preparation of spiroketals, the most common was the cyclocondensation of ketone diols [206, 207]. Nevertheless, cycloisomerization on alkynediols in the presence of gold catalyst has emerged as an efficient protocol to build complex ketal systems in just one step, providing specific benefits. For example, cycloisomerization of alkynediols with Au catalyst was more atom economical, exothermic, and more compatible than ketones under various reaction conditions. Recently, many groups have introduced the present strategy for the preparation of many natural compounds and derivatives [208-211]. Li and co-workers [212] synthesized bisbenzannelated spiroketal core of rubromycins. These natural occurring structures possess many biological properties like inhibition of the reverse transcriptase of HIV I, inhibition of DNA polymerase, or inhibition of DNA helicase [213-216]. Scheme 18 depicts the basic structure moiety shared by natural isolated compounds such
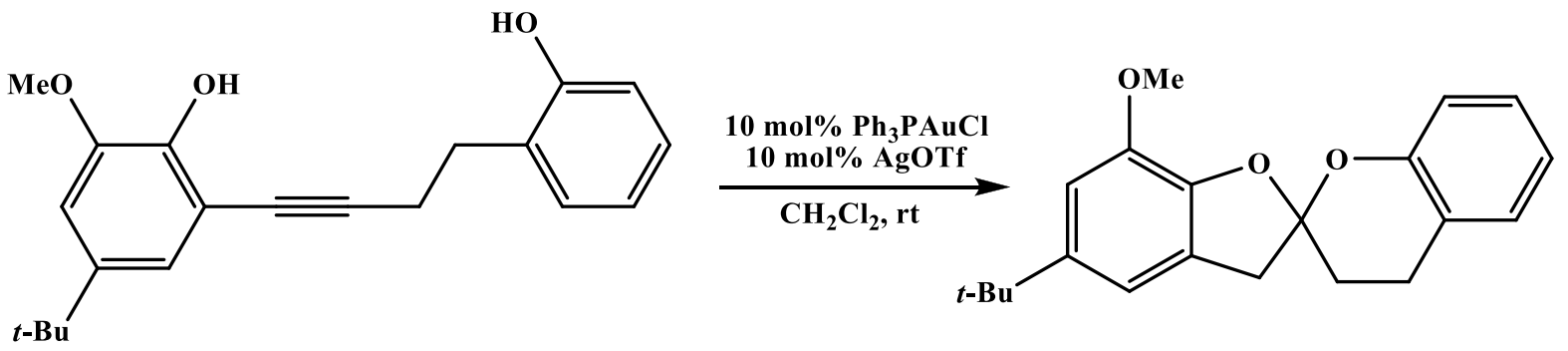

Scheme 15 Synthesis of bis-benz-annelated spiroketal core of natural bioactive rubromycins
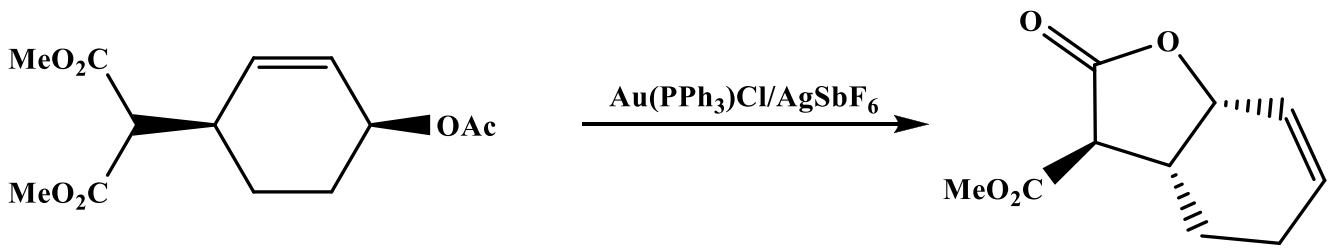

Scheme 16 Synthesis of 3,4-anti-4,5-syn-3-methoxycarbonyltetrahydrobenzobutyrolactone

Scheme 17 Synthesis of 3-carbonylated benzofuran<smiles>O=C(C/C(=N/Oc1ccccc1)c1ccccc1)c1ccccc1</smiles>

$3 \mathrm{~mol}^{\%} \mathrm{AuCl}_{3} / \mathrm{AgSbF}_{6}$ $\mathrm{CH}_{3} \mathrm{NO}_{2}, 90^{\circ} \mathrm{C}$ 


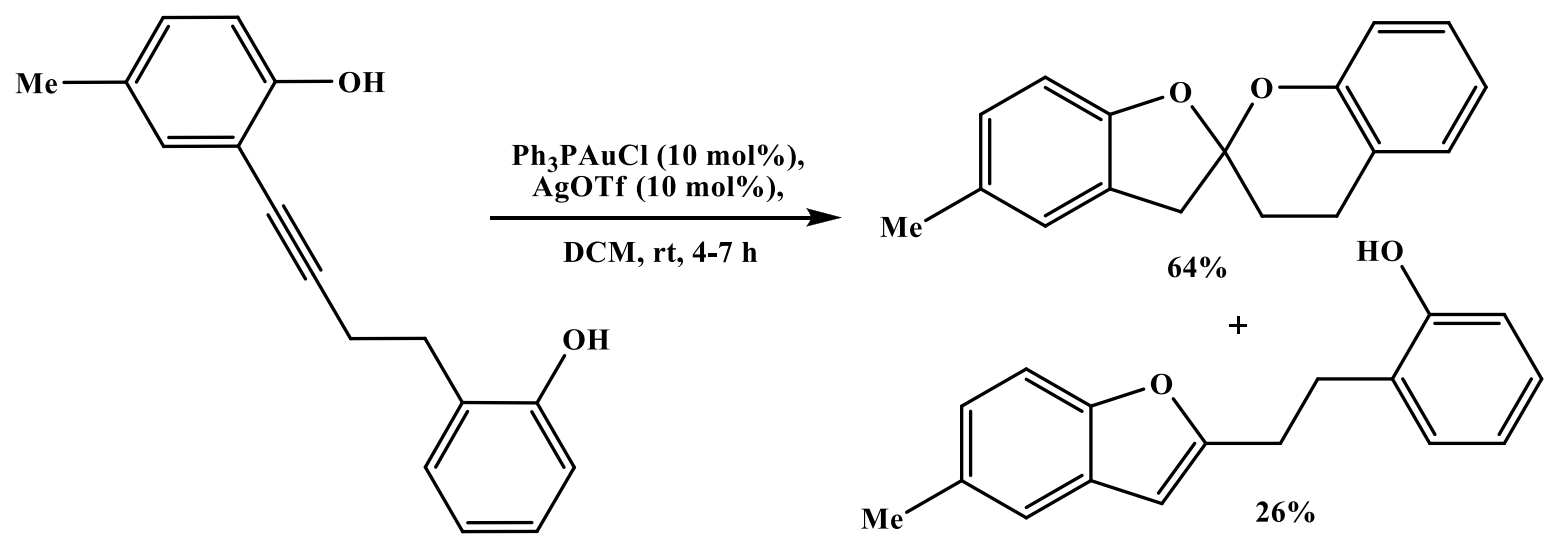

Scheme 18 Synthesis of benzofurans<smiles>COc1ccc(C(=O)C(O)O)cc1</smiles>

$\mathrm{TsNH}_{2}$

Scheme 19 Synthesis of 2-aryl-3-aminobenzofuran

as purpuromycin, $\gamma$-rubromycin, or heliquinomycin. Easily synthesized alkynediols underwent gold catalyzed cycloisomerization to afford moderate yields of spiroketals along with benzofuran in notable amounts [186].

\subsection{Indium assisted synthesis}

Chen et al. $[217,218]$ reported $\operatorname{InCl}_{3}$ catalyzed synthetic protocol for the synthesis of 2-aryl-3-aminobenzofuran derivatives by the reaction of phenols, arylglyoxal monohydrates, and $p$-toluenesulfonamide (Scheme 19). Some of the benefits are: (1) $\operatorname{lnCl}_{3}$ is easily available and economical catalyst, the formation of by-products $a$-diketones was inhibited unlike in other Lewis acid catalyzed three-component reactions; (2) this reaction is important for the synthesis of compound libraries in combinatorial chemistry as structurally diverse benzofuran derivatives were prepared from various arylglyoxal monohydrates and phenols bearing different functional groups [219].

\section{8 lodine assisted synthesis}

Tripathi et al. [220] reported a 5-exo-trig cyclization of o-allyl phenols for the preparation of dihydro-benzofurans

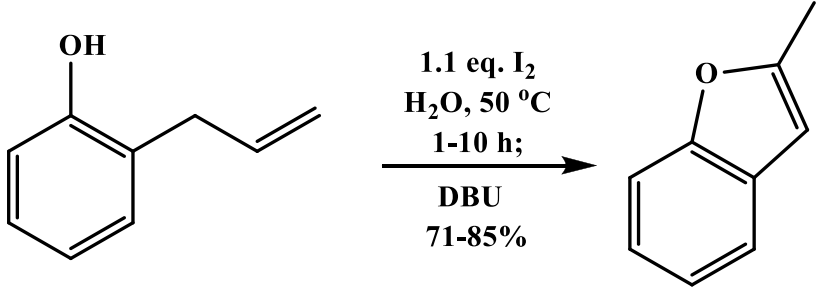

Scheme 20 Synthesis of dihydro-benzofurans

in water (Scheme 20). Products were obtained after the formation of iodoiranium intermediate followed by 5-exotrig cyclization. This method worked for phenols which contain electron withdrawing as well as donating groups. The formed dihydrofuarns were dehydrohalogenated in the presence of 1,8-diazabicyclo[5.4.0] undec-7-ene to give benzofurans [221].

Kobayashi et al. [222] reported a 5-exo-trig cyclization of o-vinylbenzyl alcohols for the synthesis of 1,3-dihydroisobenzofurans. The $o$-vinylbenzyl alcohols were prepared by the reaction of 2-vinyl phenyl lithium and carbonyl compounds (Scheme 21). The yield decreased when an electron donating group was present on the aryl ring. The 
obtained (1-iodomethyl)-1,3-dihydroisobenzofurans were then either alkylated with sodium thiolate or reduced with tributyltinhydride [221].

Larock et al. [223] reported 6-endo-dig and 5-exo-dig cyclization for the synthesis of five- and six-membered iodo heterocycle respectively from o-alkynylbenzyl alcohols (Scheme 22). The iodoirenium intermediate was formed when iodine coordinated with the carbon-carbon triple bond. Nucleophilic attack of hydroxyl group occurred by 5-exo-dig and 6-endo-dig cyclization to afford the intermediate [221].

Iminoethers act as important building blocks which were hydrolyzed under mild reaction conditions. Dienamides were transformed conveniently to iminoethers [224]. For example, the bromosubstituted iminoether was formed in 53\% yield when the starting compound was reacted with NBS. Furthermore, higher yields of halo substituted iminoether were obtained when starting compound was treated with $\mathrm{I}_{2}$ in $\mathrm{N}$-bromosuccinimide. The iodo-substituted iminoether was formed in $90 \%$ yield $[225,226]$ (Scheme 23).

The reaction conditions were modified for hetero1,3-diyne in order to achieve single or double cyclization (Scheme 24). Thus, unsymmetrical as well as symmetrical, bisheterocyclic units with dihalide moiety were easily accessible employing this protocol. Similar dihalo compounds were utilized as substrates for the preparation of more complex fused heterocyclic compounds which possess potential applications as organic field effect transistors (OFETs) [223, 227, 228].

The 2-arylbenzofurans were formed by a convenient metal-free cyclization of ortho-hydroxystilbenes in the presence of hypervalent iodine reagents. Desired products were obtained in good yields employing stoichiometric (diacetoxyiodo)benzene in $\mathrm{CH}_{3} \mathrm{CN}$ [229] (Scheme 25).

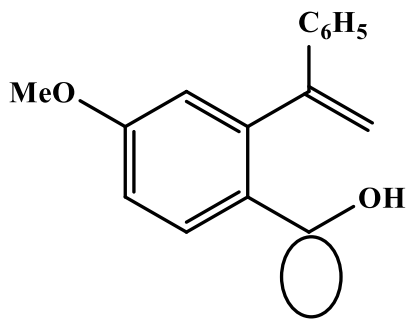

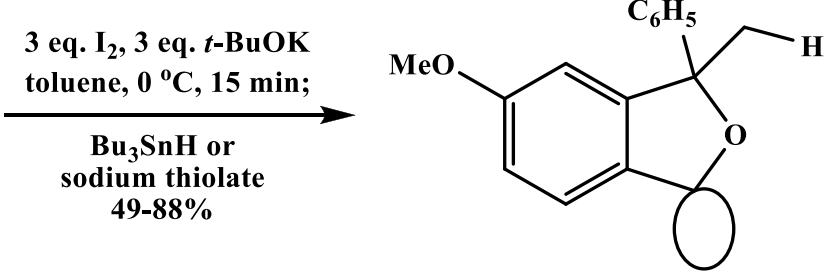

Scheme 21 Synthesis of 1,3-dihydroisobenzofurans

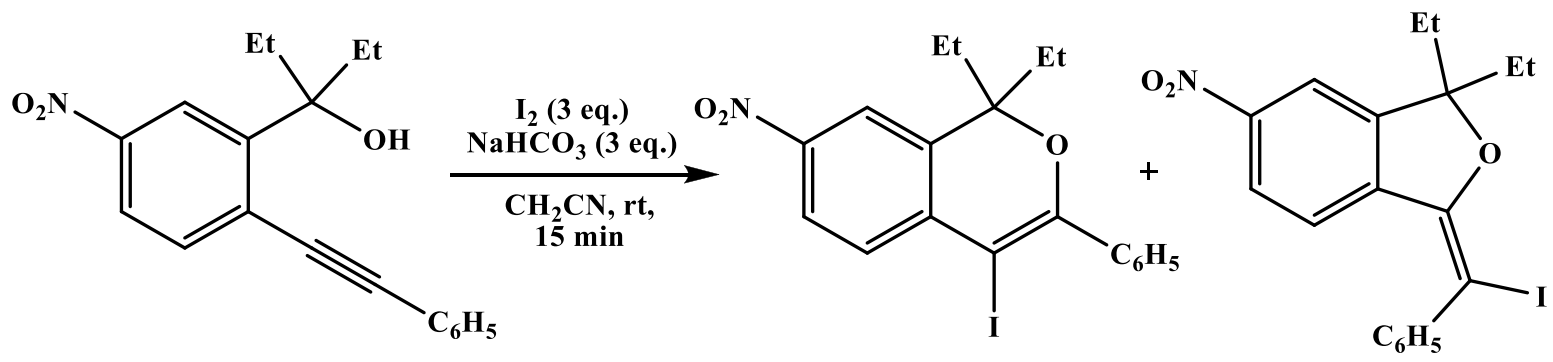

Scheme 22 Synthesis of 1,1-diethyl-4-iodo-7-nitro-3-phenyl-1H-isochromene and (Z)-1,1-diethyl-3-(iodo(phenyl)methylene)-6-nitro-1,3-dihydroisobenzofuran<smiles>C=C1CC(C(=O)OCC)(C(=O)OCC)C(C(=O)OCC)(C(=O)OCC)CC1=C(C)C(=O)NCc1ccccc1</smiles>

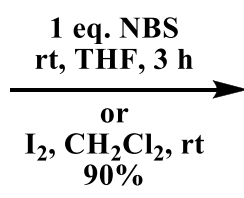<smiles>CCOC(=O)C1(C(=O)OCC)CC2=C(C)C(=NCc3ccccc3)OC2(CI)CC1(C(=O)OCC)C(=O)OCC</smiles>

Scheme 23 Synthesis of (E)-tetraethyl 2-(benzylimino)-7a-(iodomethyl)-3-methyl-7,7a-dihydrobenzofuran-5,5,6,6(2H,4H)-tetracarboxylate 


\subsection{Iron assisted synthesis}

The coupling reactions with both non-substituted and $\mathrm{N}$-benzylsubstituted 2-iodoaniline as the arylating agents were very clean, and selectively afforded the high yields of Sonogashira coupling products, without any side reactions on the amine functionality. On the other hand, when 2-iodophenol was utilized, benzofurans were formed from domino Sonogashira coupling reactions followed by intramolecular hydroalkoxylations in moderate yields together with recovered aryl acetylenes (Scheme 26). Although the utilization of iron catalysts and $\mathrm{Ag}$ additives for the addition of a hydroxy functionality to olefins is known [230], to the best of knowledge these were the first noted exclusive ironcatalyzed hydroalkoxylations of alkynes. Further experiments, to expand the substrate scope and to improve the conversions of this unprecedented transformation, are currently under study.

\subsection{Lithium assisted synthesis}

Acetylene-based compounds are very important in synthetic chemistry. The alkynes underwent $[2+2+2]$ cyclotrimerization to provide hexasubstitiuted benzenes in one step [231-235]. They acted as useful intermediates for the preparation of biologically active and naturally occurring compounds like dehydrotremetone [236], lunularic acid [237], and cicerfuran [238]. The acetylene functionality was also used in compounds which possess interesting optical, electronic, and other materials-based properties [239-244]. Several acetylenic-based compounds were reported for use as nonlinear optics and molecular wires $[245,246]$ (Scheme 27).

The thianthrene was submitted to reaction as shown in Scheme 28, after reacting with a first carbonyl compound, the lithiation was continued at -90 to $-78^{\circ} \mathrm{C}$ with second carbonyl compound, a second carbonsulfur cleavage occurred to provide organolithium intermediate which was reacted with the electrophile present in the reaction medium to give diols [247-249]. These diols were cyclized with $85 \%$ phosphoric acid

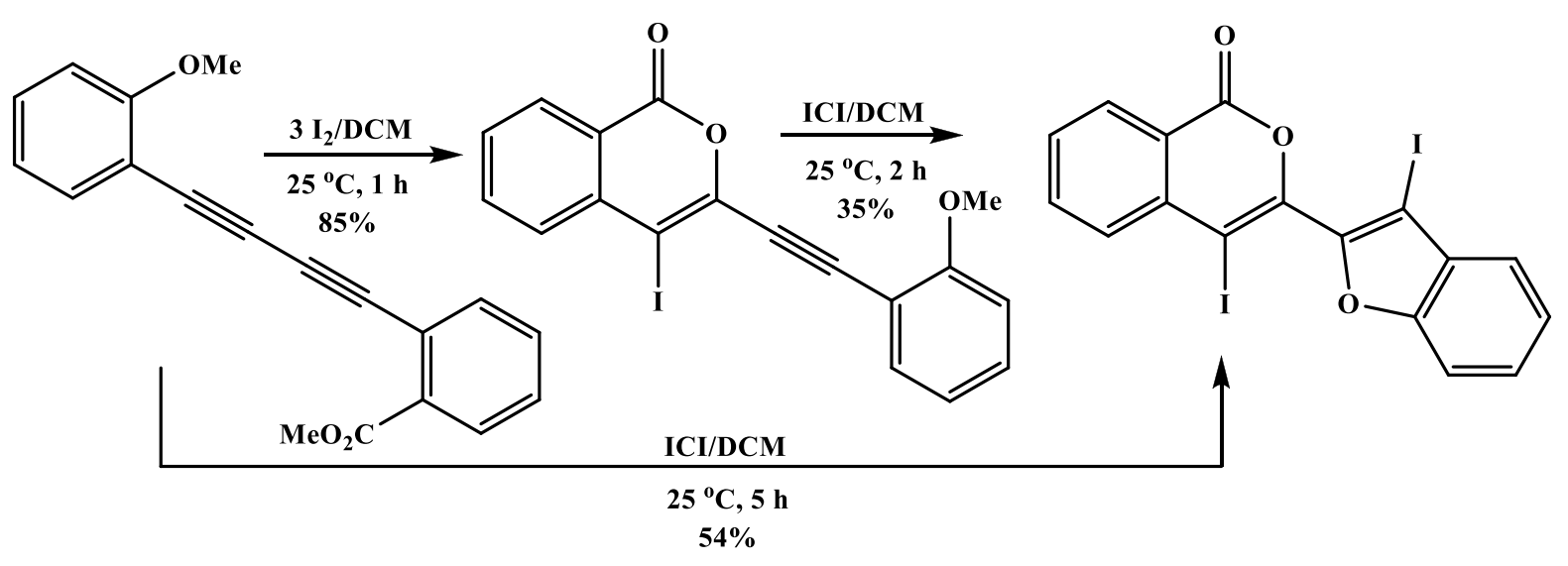

Scheme 24 Synthesis of 4-iodo-3-(3-iodobenzofuran-2-yl)-1H-isochromen-1-one

Scheme 25 Synthesis of 2-arylbenzofurans<smiles>Oc1ccccc1/C=C/c1ccccc1</smiles>

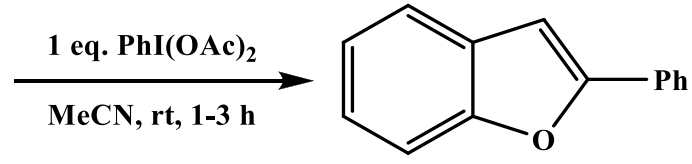<smiles>C#Cc1ccccc1</smiles><smiles>Oc1ccccc1I</smiles>

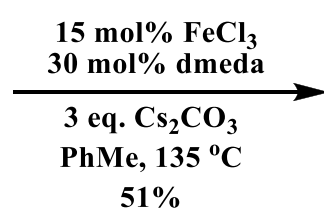<smiles>c1ccc(-c2cc3ccccc3o2)cc1</smiles>

Scheme 26 Synthesis of 2-phenylbenzofuran 
<smiles>C=C(C)C#Cc1cc(C=O)ccc1OC</smiles><smiles>C=C(C)c1cc2cc(C(=O)NC3CCCCC3)ccc2o1</smiles>

Scheme 27 Synthesis of 2-(prop-1-en-2-yl)benzofuran-5-carbaldehyde<smiles>c1ccc2c(c1)Sc1ccccc1S2</smiles>

Li, DTBB (5\%), THF, $-90{ }^{\circ} \mathrm{C}$; $\mathrm{PhCHO}, \mathrm{Me}_{2} \mathrm{CO}, \mathrm{Et}_{2} \mathrm{CO}$, $\left(\mathrm{CH}_{2}\right)_{5} \mathrm{CO},-90{ }^{\circ} \mathrm{C}$

$\mathrm{Ph}\left(\mathrm{CH}_{2}\right)_{2} \mathrm{CHO}, \mathrm{Me}_{2} \mathrm{CO}$, $\mathrm{Et}_{2} \mathrm{CO}, \mathrm{CO}_{2},-90$ to $-78{ }^{\circ} \mathrm{C}$; $\mathrm{H}_{2} \mathrm{O},-78^{\circ} \mathrm{C}$ to $\mathrm{rt}$; $42-68 \%$<smiles>CC(C)(O)c1ccccc1C(O)c1ccccc1</smiles>

Scheme 28 Synthesis of 1,1-dimethyl-3-phenyl-1,3-dihydroisobenzofuran

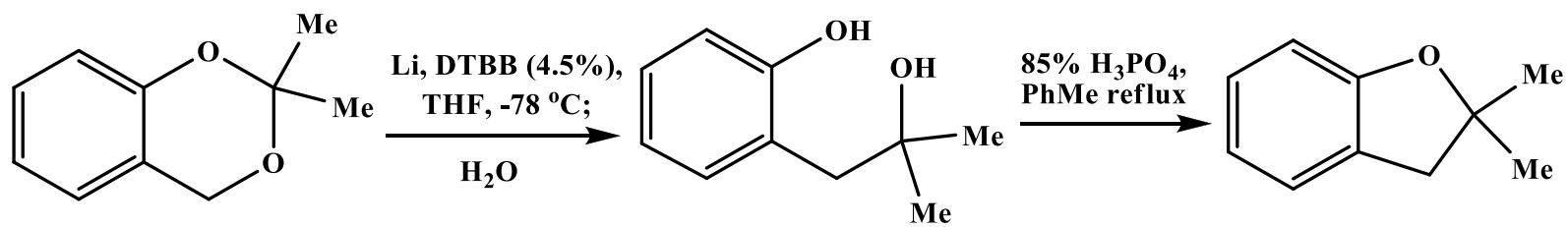

Scheme 29 Synthesis of 2,2-dimethyl-2,3-dihydrobenzofuran<smiles>Oc1ccccc1C#Cc1ccccc1</smiles>

$+\quad \mathbf{P h}-\mathbf{I}$
$5 \mathrm{~mol} \% \mathrm{Pd}\left(\mathrm{Ph}_{3} \mathrm{P}\right)_{4}$ $\underset{30 \%}{5 \mathrm{~mol}^{2} \mathrm{AgBF}_{4}, \mathrm{~K}_{2} \mathrm{CO}_{3}}$
$\underset{30}{\mathrm{Bu}_{2} \mathrm{O}, \mathrm{CO},{ }^{\circ} \mathrm{C}}$<smiles>O=C(c1ccccc1)c1c(-c2ccccc2)oc2ccccc12</smiles>

Scheme 30 Synthesis of 3-aroyl-benzo[b]furans

under reflux in toluene to synthesize the substituted phthalans [250].

The 1,3-dioxanes were reacted with catalytic amount of $4,4^{\prime}$-di-tert-butylbiphenyl and lithium at $-78^{\circ} \mathrm{C}$ in tetrahydrofuran to produce an intermediate, which underwent intramolecular nucleophilic substitution to form compounds (Scheme 29) [251]. These hydroxy phenols were cyclized under acidic conditions to give benzofused heterocyclic compounds [250].

\subsection{Palladium assisted synthesis}

Yang et al. [252] reported that cationic Pd complexes showed high reactivity toward coordination of alkynes or alkenes for efficient carbonylation processes. These cationic complexes were easily synthesized in situ by reaction of $\mathrm{Ag}$ salts of $\mathrm{ClO}_{4}^{-}, \mathrm{BF}_{4}^{-}$, and $\mathrm{BAr}_{4}{ }^{-}$with organopalladium halides in the presence of chelating diamine (diimine) ligands or tertiary phosphine ligands. The starting 


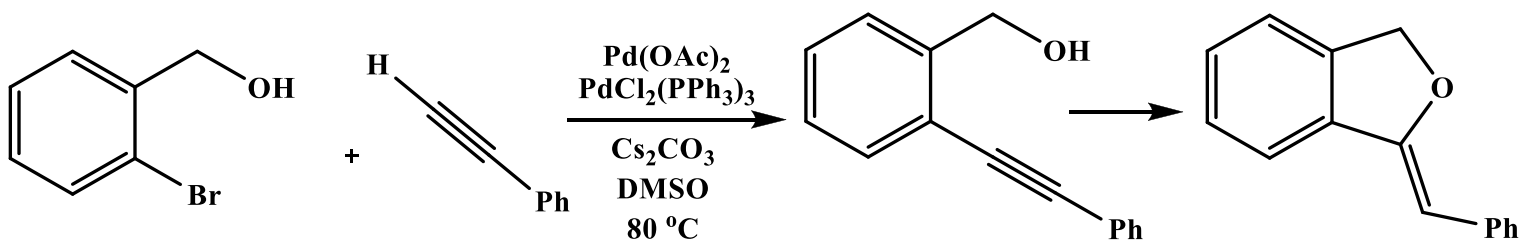

Scheme 31 Synthesis of (Z)-1-benzylidene-1,3-dihydroisobenzofuran<smiles>O=C(Oc1ccccc1)c1ccc(O)c(I)c1</smiles>

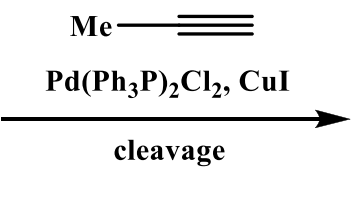<smiles>Cc1cc2cc(C(=O)O)ccc2o1</smiles>

Scheme 32 Synthesis of 2-substituted benzofurans<smiles>[X]c1ccc(O)c(I)c1</smiles>

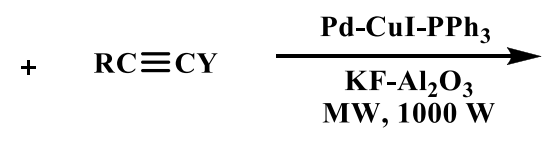<smiles>[X]c1ccc2oc([R])cc2c1</smiles>

Scheme 33 Synthesis of substituted benzofurans

Scheme 34 Synthesis of substituted benzofurans

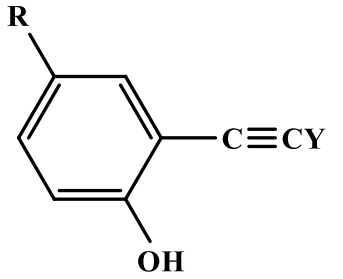

$+$

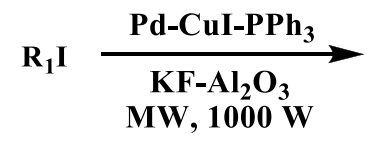<smiles>[R]c1ccc2oc([R])cc2c1</smiles>

substrate was not converted into 3-aroyl-benzo[b]furans in the absence of Ag-salt, only phenol ester was obtained (Scheme 30). An complex intermediate was produced from organopalladium iodide. This complex bear a cationic metal center with Lewis acid character and coordinated strongly with unsatured triple bond [253].

The tandem process shown in Scheme 31 comprised an intermolecular Sonogashira coupling and an intramolecular cyclic hydroalkoxylation $[254,255]$. The $\mathrm{C}-\mathrm{C}$ bond formation occurred in the absence of additives other than the base. The cyclization reaction was highly selective towards five-membered ring and $Z$ isomer. Neither the six-membered ring nor the $E$ isomer were formed. The final product was obtained from o-iodobenzyl alcohol in full conversions ( $95 \%$ yield) in less than $1 \mathrm{~h}$. The higher catalytic activity was observed for complex as compared to the ubiquitous palladium acetate and $\mathrm{PdCl}_{2}\left(\mathrm{PPh}_{3}\right)_{3}$ under same reaction conditions.
Fancelli and co-workers [256] reported a Cu/Pd heteroannulation of terminal acetylenes with resin bound aryl iodides to synthesize 2-substituted benzofurans (Scheme 32) [37].

Kabalka et al. [257] reported a microwave-assisted solvent-free Sonogashira coupling of iodophenol with terminal alkynes on KF doped alumina for the synthesis of benzofurans (Scheme 33). The o-ethynylphenols were reacted with aryl or alkyl iodides to afford the moderate yields of substituted benzofurans (Scheme 34) [38].

The racemic propargylglycine derivative was reacted with 2-iodophenol under Sonogashira coupling conditions to provide the appropriate precursor in order to investigate the possible synthesis of a 2-substituted benzo[b] furan via Ag- or palladium-catalyzed intramolecular reaction (Scheme 35). The expected precursor was formed in $64 \%$ yield under these conditions, but in addition $16 \%$ yield of the eventually desired tryptophan analogue 

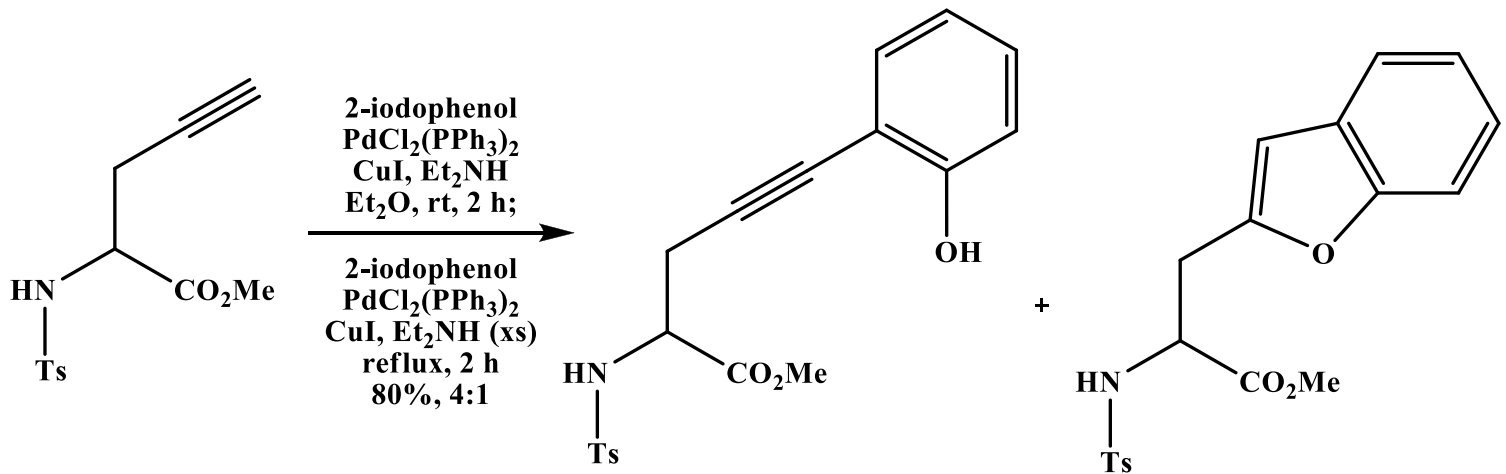

Scheme 35 Synthesis of 2-substituted benzo[b]furan

was obtained. The obtained mixture without separation was subjected to AgOTf in refluxing $\mathrm{CH}_{3} \mathrm{CN}$ to examine whether this catalyst would effect the cyclization of phenol into benzofuran. Unfortunately, however, no increase in the conversion of phenol into benzofuran was reported when the mixture was refluxed in the presence of AgOTf for more than $20 \mathrm{~h}$. This was due to the lower nucleophilicity of the phenol in comparison to the anilines. Therefore, diethylamine (1 eq.) was added to the reaction mixture to examine if this would facilitate the synthesis of benzofuran. Indeed, phenol was converted into benzofuran rapidly upon the addition of diethylamine, however, the reaction led to partial decomposition of the remaining phenol and also did not go to completion. Thus, a mixture of phenol and benzofuran was formed in a combined yield of $71 \%$ and an improved ratio in favor of benzofuran when acetylene was subjected to modified conditions [258].

For this tandem cross-coupling cyclization reaction, [259-261] authors transformed enantiomerically pure propargylglycine into propargylglycine derivative by esterification utilizing thionyl chloride in methanol and subjected it to $p$-toluenesulfonyl chloride and pyridine in dichloromethane. Subsequently, acetylene was reacted with 2-iodophenol under modified Sonogashira conditions to provide the intermediate phenol, which was completely consumed after $4 \mathrm{~h}$ to afford the enantiopure tryptophan analogue in $74 \%$ yield as the sole product (Scheme 36 ) [258].

Hosokawa et al. [262] reported palladium(II)-catalyzed intramolecular processes for carbon-oxygen bond formation and developed the cyclization of 2-allylphenols to afford oxygen-containing heterocyclic compounds. However, the nature of palladium(II) salt affected the regioselectivity of the reaction to produce the five- or sixmembered rings (Scheme 37). The six-membered products were formed predominantly in the presence of sodium salts of carboxylic acids containing electron-withdrawing substituents [263].

As compared to $o$-iodoanilines, $o$-iodophenols were utilized to produce the benzofurans in a one-pot protocol (Scheme 38). Cacchi and co-workers [264] utilized cuprous iodide and $\mathrm{Pd}(\mathrm{OAC})_{2}\left(\mathrm{PPh}_{3}\right)_{2}$ for the synthesis of variously substituted benzofurans from acetylenic derivatives and 2-iodophenols in $25-88 \%$ yield. This method was extended to the synthesis of furo[3,2-b]pyridines. This Pd catalyzed activation of alkynes toward nucleophilic attack was also adapted to oxygen nucleophiles to afford a pathway for the synthesis of benzofurans.
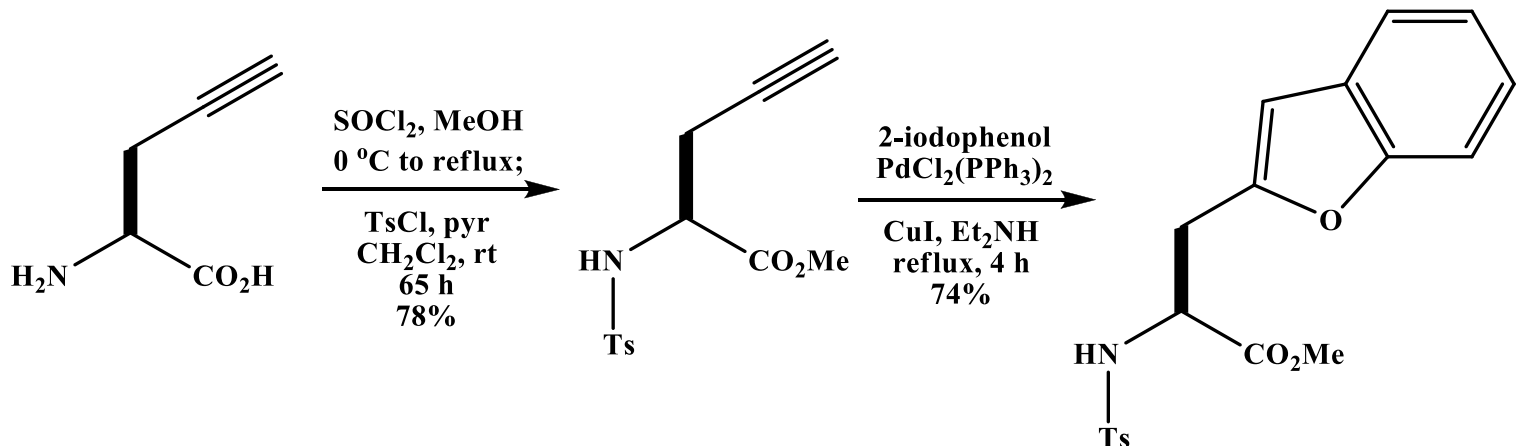

Scheme 36 Synthesis of tryptophan analogue 
Cacchi [265] applied this in palladium acetate/cuprous iodide catalyzed Sonogashira coupling/cyclization of 2-halophenols with terminal alkynes. This approach has been expanded to the preparation of a variety of substituted benzofurans and related products, where the phenol unit was replaced with heterocyclic compounds, benzoqunione derivatives, and other polycyclic aromatic units [266-268].

The benzopyrone is present in various natural products such as flavonoids which interact with several receptor systems and enzymes of biological importance. Acyl chlorides derived from protected salicylic acids were utilized in Sonogashira coupling with terminal alkynes [269]. Benzopyrones were synthesized from alkynones by 6-endo cyclization under controlled conditions which preclude synthesis of aurones (Scheme 39).

The domino reaction for the synthesis of dihydroisobenzofuran was successfully transformed into a threecomponent reaction involving a one-pot coupling/ addition/cyclization sequence promoted by a base and Pd [270] (Scheme 40).

Different result was reported when 2-bromonicotinaldehyde was reacted with triethylsilylacetylene (TES). The main product was formed together with the desired desilylated compound in minor amounts. This was due to an early desilylation route occurring after the Sonogashira coupling, followed by a second coupling of terminal acetylene with 2-bromonicotinaldehyde, and a final addition/ cyclization step (Scheme 41) [271-273].

The $(E)$-1,2-diiodoalkenes were reacted with terminal alkynes at room temperature in the presence of $\mathrm{Cul}$ and $\mathrm{Pd}(\mathrm{OAc})_{2}$ to provide unsymmetrical buta-1,3-diynes selectively in moderate to good yields. The coupling of 2-ethynylphenol occurred with (E)-1,2-diiodoalkenes under same conditions, followed by a cyclization at $100{ }^{\circ} \mathrm{C}$ to afford ethynylbenzofurans [274] (Scheme 42).

The stoichiometric Pd reagents were utilized for several decades to assist this reaction, cyclization occurred

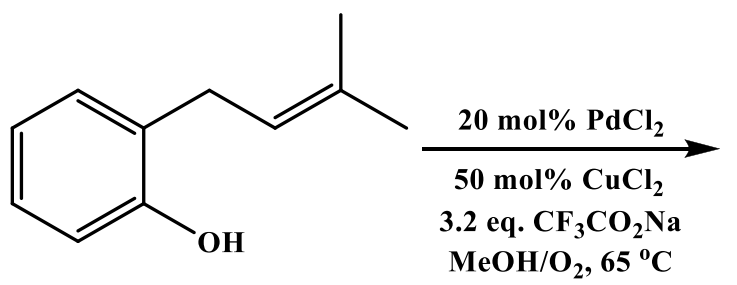<smiles>CC1(C)C=Cc2ccccc2O1</smiles><smiles>CC(C)c1cc2ccccc2o1</smiles><smiles>C=C(C)c1cc2ccccc2o1</smiles>

Scheme 37 Synthesis of 2,2-dimethyl-2H-chromene, 2-isopropylbenzofuran and 2-(prop-1-en-2-yl)benzofuran<smiles>Oc1ccccc1Br</smiles><smiles>C#C[PH2+]c1ccccc1</smiles><smiles>c1ccc(-c2cc3ccccc3o2)cc1</smiles>

Scheme 38 Synthesis of 2-phenylbenzofuran

Scheme 39 Synthesis of 2-methyl-4H-chromen-4-one and (Z)-2-ethylidene-3-oxo2,3-dihydrobenzofuran-5-ylium

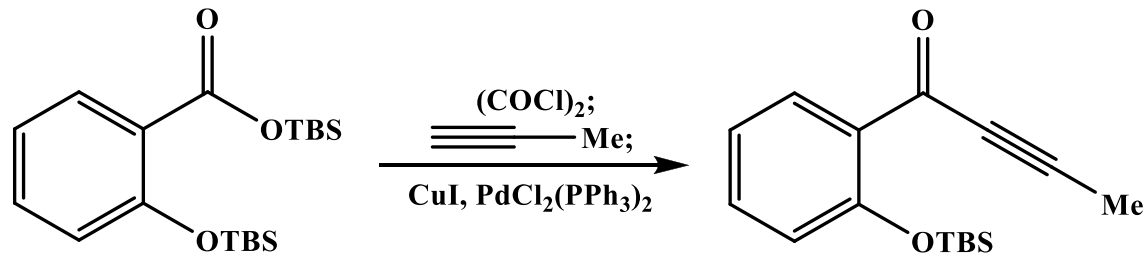<smiles>CCNC(CC)[C@H](CC)NCC</smiles> 
<smiles>C#C[PH+]c1ccccc1</smiles>

Scheme 40 Synthesis of dihydroisobenzofuran

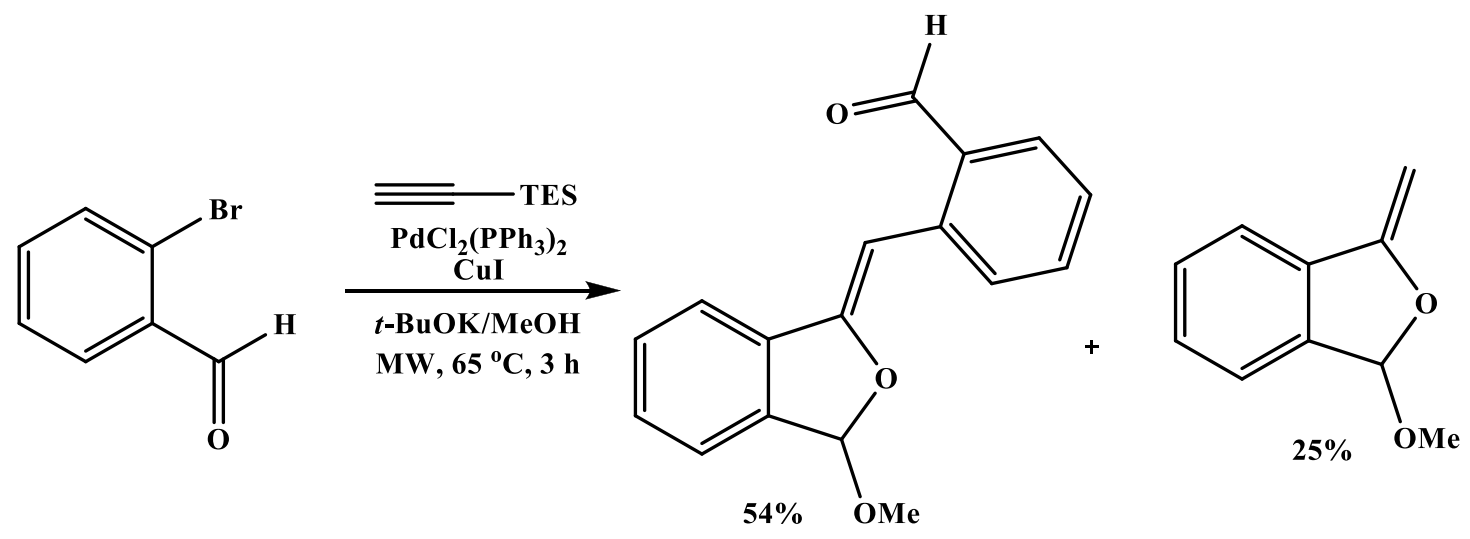

Scheme 41 Synthesis of (Z)-2-((3-methoxyisobenzofuran-1(3H)-ylidene)methyl)benzaldehyde and 1-methoxy-3-methylene-1,3-dihydroisobenzofuran

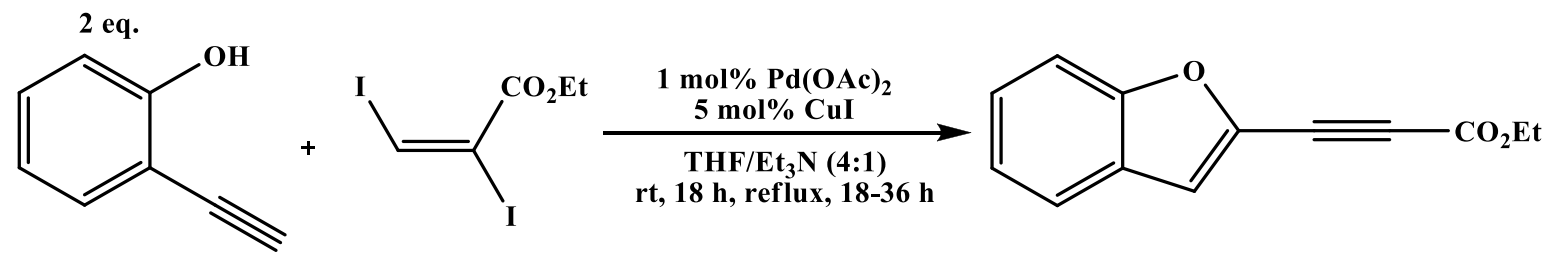

Scheme 42 Synthesis of ethynylbenzofurans

Scheme 43 Synthesis of 2-ethylbenzofuran<smiles>C/C=C\Cc1ccccc1O</smiles>

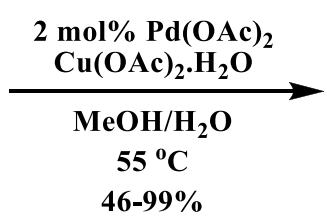<smiles>Cc1cc2ccccc2o1</smiles>

with reduction to $\mathrm{Pd}(0)$, which was inactive for further reaction [275-277]. It was reported that the addition of stoichiometric oxidants like $\mathrm{Cu}$ (II) salts allowed the catalytic cyclization. For example, Hosokawa [278] observed that the catalytic cyclization of 2-allylphenols to benzofurans occurred upon the addition of copper acetate in the presence of oxygen and $2 \mathrm{~mol} \%$ palladium acetate
(Scheme 43). This reaction occurred with good diversity and even at ambient temperature in water/DMF solvent.

Kundu et al. [279] reported the synthesis of Z-3-alkylidenephthalides as major products by $\mathrm{Pd} / \mathrm{Cu}$-catalyzed heteroannulation of $o$-iodobenzoic acids with terminal alkynes (Scheme 44). Phthalides were formed exclusively in many cases. The heteroannulation approach 
Scheme 44 Synthesis of

Z-3-alkylidenephthalides<smiles>O=C(O)c1ccccc1I</smiles><smiles>O=C1O/C(=C\c2ccccc2)c2ccccc21</smiles>

was completely stereospecific, since only Z-isomers were formed.

\subsection{Rhodium assisted synthesis}

The ring systems were prepared, as shown by the total synthesis of (+)-eleman-8,12-olide, by intramolecular sulfur ylide formation and subsequent [2,3]-sigmatropic rearrangement (Scheme 45) [280-282]. The core structure was constructed from diazoketo esters in one step by rhodium acetate catalyzed reaction of intramolecular sulfonium ylide followed by [2,3]-sigmatropic rearrangement. The rearrangement occurred with high diastereoselectivity. Recently sulfonium ylide [2,3]-sigmatropic rearrangement was studied focusing on the development of new catalytic systems, including alternative carbene precursor other than commonly used diazocarbonyl compounds and new catalysts. Besides the most commonly used rhodium(II) and copper(I) catalysts, ruthenium [283, 284] and iron [285] complexes were utilized to catalyze the decomposition of diazo compounds to produce a metal carbene complex, which was trapped by allyl sulfide to induce $[2,3]$-sigmatropic rearrangement. For the carbene precursor, commercially available trimethylsilyldiazomethane was utilized which have some benefits over the conventional diazocarbonyl compounds [286, 287]. A unique and interesting catalytic system, in which the rhodium(II) intermediate was produced by rhodium acetate catalyzed reaction of conjugated ene-yne-carbonyl compounds.

The conjugated ene-yne-carbonyl compounds underwent rhodium-mediated rearrangement for the synthesis of (2-furyl)carbenoids. The S-ylide formation occurred with subsequent 2,3-sigmatropic rearrangement in the presence of 10 equiv of an allyl sulfide, in analogy to the Doyle-Kirmse reaction of allyl sulfides with diazo compounds (Scheme 46) [288-291]. Good to excellent yields of coupling products were obtained, with an additional advantage that there was no need for slow addition of the carbene precursor. With diallyl sulfide, the reaction was performed at higher temperature to provide an access to subsequent Diels-Alder reaction with significant formation of complexity under mild reaction conditions. It was reported that the reaction of starting material with allylic sulfides occurred in catalytic amounts of rhodium acetate, and the furan possessing sulfides were formed in excellent yields [78-87, 111, 292].

The catalytic carbon-hydrogen insertion to metal carbenoids (derived from diazo compounds) occurred with chiral transition-metal catalysts in an enantioselective

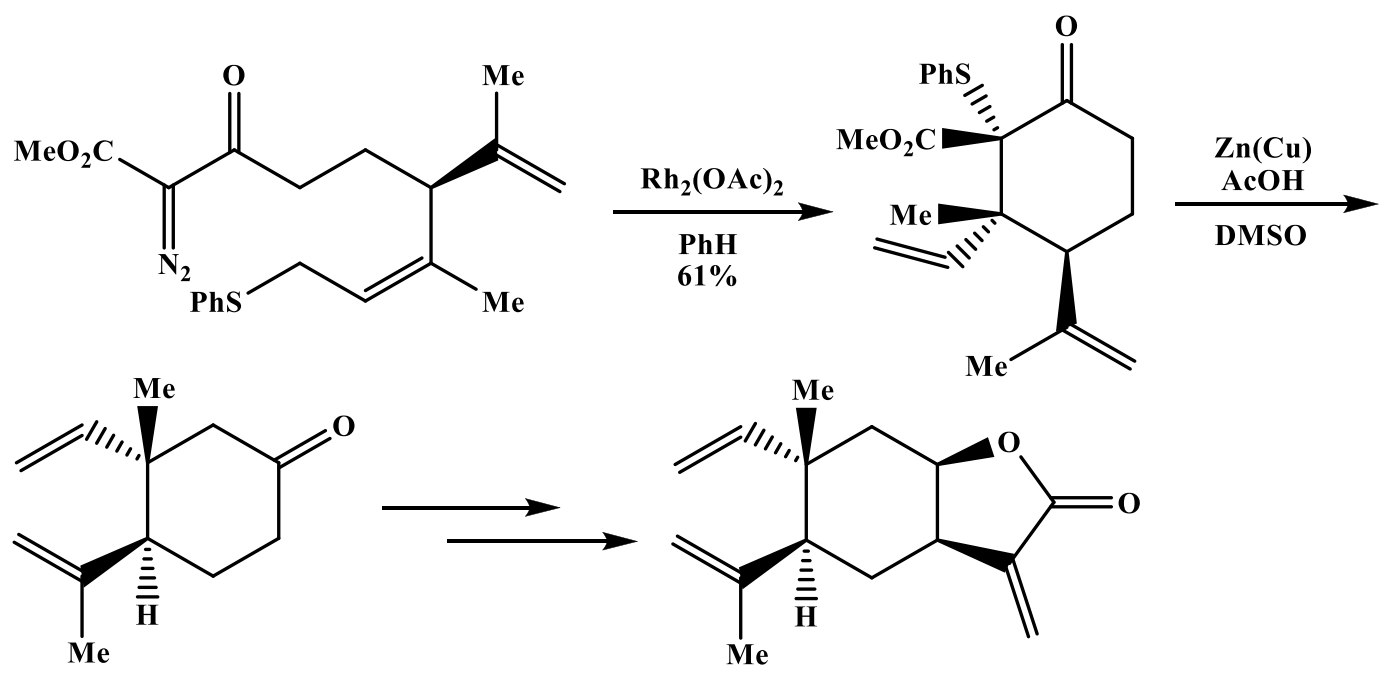

Scheme 45 Synthesis of (3aR,5S,6S,7aR)-6-methyl-3-methylene-5-(prop-1-en-2-yl)-6-vinylhexahydrobenzofuran-2(3H)-one 
manner. Davies and co-workers [293] reported that aryldiazoacetates underwent asymmetric intramolecular reaction in the presence of $\mathrm{Rh}_{2}$-(S-DOSP) $)_{4}$ to afford the carbon-hydrogen insertion products (Scheme 47). The enantioselectivity strongly depends on the site of the carbon-hydrogen activation; the highest enantioselectivity was reported for insertion into the methyne carbon-hydrogen bond [78-87].

Similar to sulfur ylide synthesis, carbine transfer to phosphines, which sequentially underwent a Wittig type condensation with formyl groups, afforded phosphorus ylides. The catalytic reaction of carbonyl-ene-yne monomer bearing a formyl group was employed to the polycondensation reaction which provided $\pi$-conjugated polymers with low polydispersity (Scheme 48) [294-296]. The low polydispersity was maybe due to the low concentration of ylides but also to the selective reaction between the formed oligomeric ylides and a monomer substrate (carbonyl-ene-yne) involving a highly electrophilic formyl group para to a ketone functionality [111].
Stereoselective oxonium ylide reaction, especially asymmetric catalysis, has been a problem of considerable challenge in this field [297]. Since the first report of McKervey et al. [298] in the asymmetric induction of metal carbene-assited ylide formation/[2,3]-sigmatropic rearrangement in 1992, efforts are being directed to this area. However, only limited success has been achieved so far. Following the initial use of dirhodium(II) tetrakis[(R)binaphtholphosphate] $\left[\mathrm{Rh}_{2}(\mathrm{R}-\mathrm{BNP})_{4}\right]$ where up to $30 \%$ enantiomeric excess was reported for the reaction of starting substrate, a variety of other chiral rhodium(II) catalysts [299-303] have been examined and up to $76 \%$ enantiomeric excess was obtained with Hashimoto's dirhodium(II) tetrakis[ $N$-phthaloyl-(S)-tert-leucinate] $\left[\mathrm{Rh}_{2}(\mathrm{~S}-\mathrm{PTTL})_{4}\right]$ (Scheme 49) [287].

The enantio-enriched lactones [304, 305], chromanones [306], lactams [307], and cyclopentanones [308] were synthesized by asymmetric carbocyclizations on the basis of intramolecular carbon-hydrogen insertion of chiral rhodium carbenes. These reactions occurred with moderate

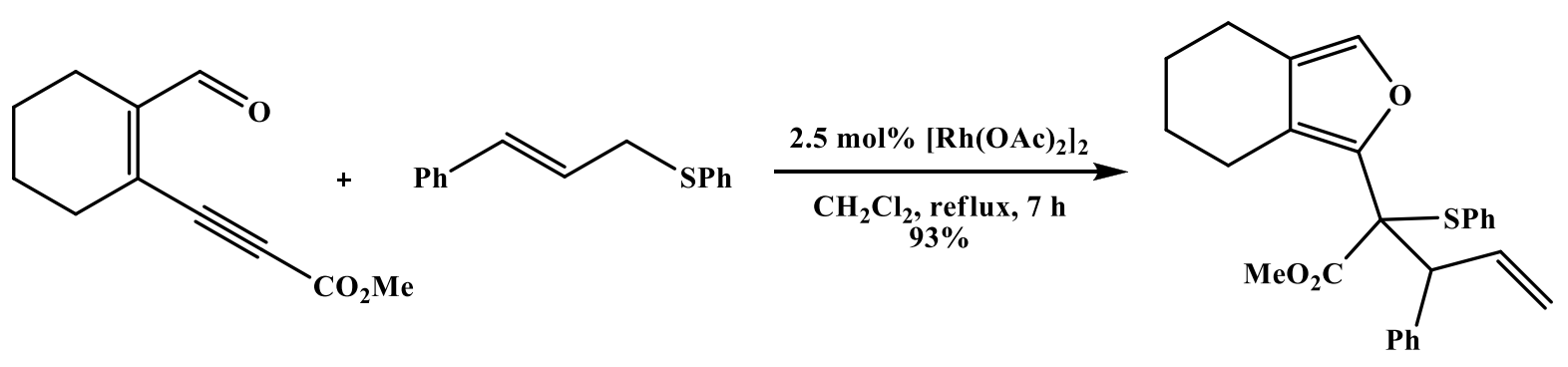

Scheme 46 Synthesis of (2-furyl)carbenoids

Scheme 47 Synthesis of (S)methyl 2,2-dimethyl-2,3-dihydrobenzofuran-3-carboxylate<smiles>COC(=O)C(=[W])c1ccccc1OC(C)C</smiles><smiles>[R12]C(C)OC(OCC)[C@H]1CCCN1S(=O)(=O)O</smiles><smiles>CC(=O)[C@H]1c2ccccc2OC1(C)C</smiles>
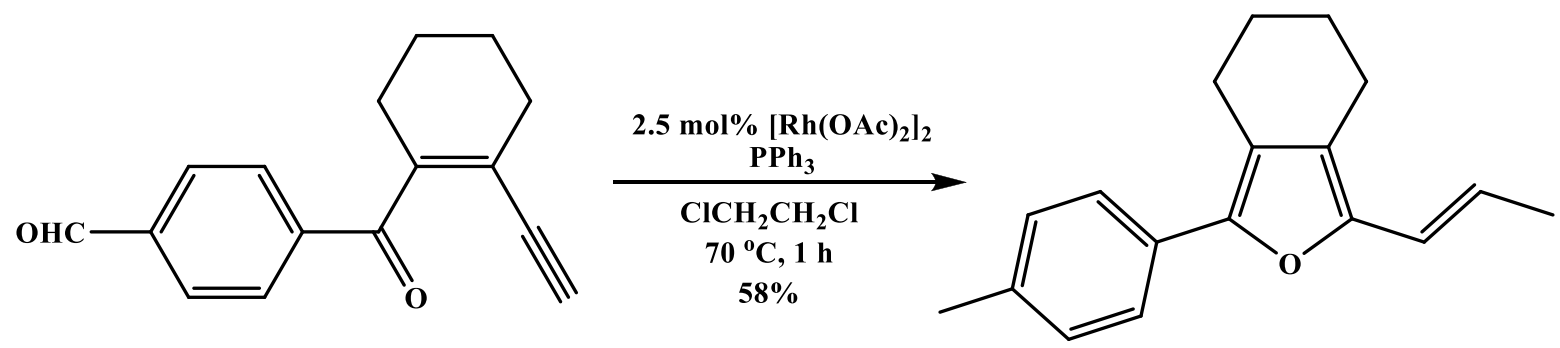

Scheme 48 Synthesis of (E)-1-(prop-1-enyl)-3-p-tolyl-4,5,6,7-tetrahydroisobenzofuran 
to excellent enantioselectivity. Excellent enantio- as well as diastereoselectivity was achieved in the reactions of diazoacetates utilizing $\mathrm{Rh}_{2}(4 \mathrm{~S}-\mathrm{MACIM})_{4}$ methyl 1-acetyl2-oxoimidazolidine-4S-carboxylate as a chiral catalyst, which afforded bicyclic lactones with $96-97 \%$ enantiomeric excess and 98\% de [309] (Scheme 50).

Chung et al. [310] reported an intramolecular [5+2] and $[4+2]$ cycloadditions in the presence of $[(\mathrm{IPr}) \mathrm{Rh}(\mathrm{COD}) \mathrm{Cl}]$ catalyst in conjunction with $\mathrm{Ag}(\mathrm{I})$ salt. This catalytic system was highly efficient for these two cyclizations, synthesizing, respectively, bicyclo[5.3.0]nonadiene and bicyclo[4.3.0] octadiene derivatives in high yields (Scheme 51). Despite the high activity reported for these intramolecular reactions, this system was not effective for intermolecular [5+2] cycloaddition [143].

The long-chain molecules were constructed, important in materials science, by $[2+2+2]$ cycloaddition of alkynes.
McDonald et al. [311] reported the novel preparation of oligo-p-phenylenes, involving alkyne trimerization in the presence of rhodium catalyst as a key step (Scheme 52). Some phenylene products were useful in the construction of light-emitting and organic conducting polymers and were remarkably soluble in organic solvents. This type of multiple $[2+2+2]$ cyclotrimerization reaction was a unique example so far [230, 312].

Witulski and co-workers [313] used Wilkinson's catalyst for the synthesis of chiral 3-substituted phthalides. Various $a, \omega$-dialkynes were synthesized either through Mitsunobu coupling reactions or by standard dicyclohexylcarbodiimide (DCC) coupling reactions between the propargylic acid and propargyl alcohol derivatives. Chiral phthalide derivative was formed in good to excellent yields when dialkyne was treated with acetylene with the help of Wilkinson's catalyst (Scheme 53). The best results were reported when

Scheme 49 Synthesis of (R)-methyl 2-allyl-7-methyl3-oxo-2,3-dihydrobenzofuran2-carboxylate<smiles>C=CCOc1c(C)cccc1C(=O)C(=N)C(=O)OC</smiles><smiles>C=CC[C@]1(C(C)=O)Oc2c(C)cccc2C1=O</smiles>

Scheme 50 Synthesis of (3aS,7aS)-hexahydrobenzofuran-2(3H)-one<smiles>CC(C)C1CCC[C@H]2CC(=O)O[C@@H]2C1</smiles>
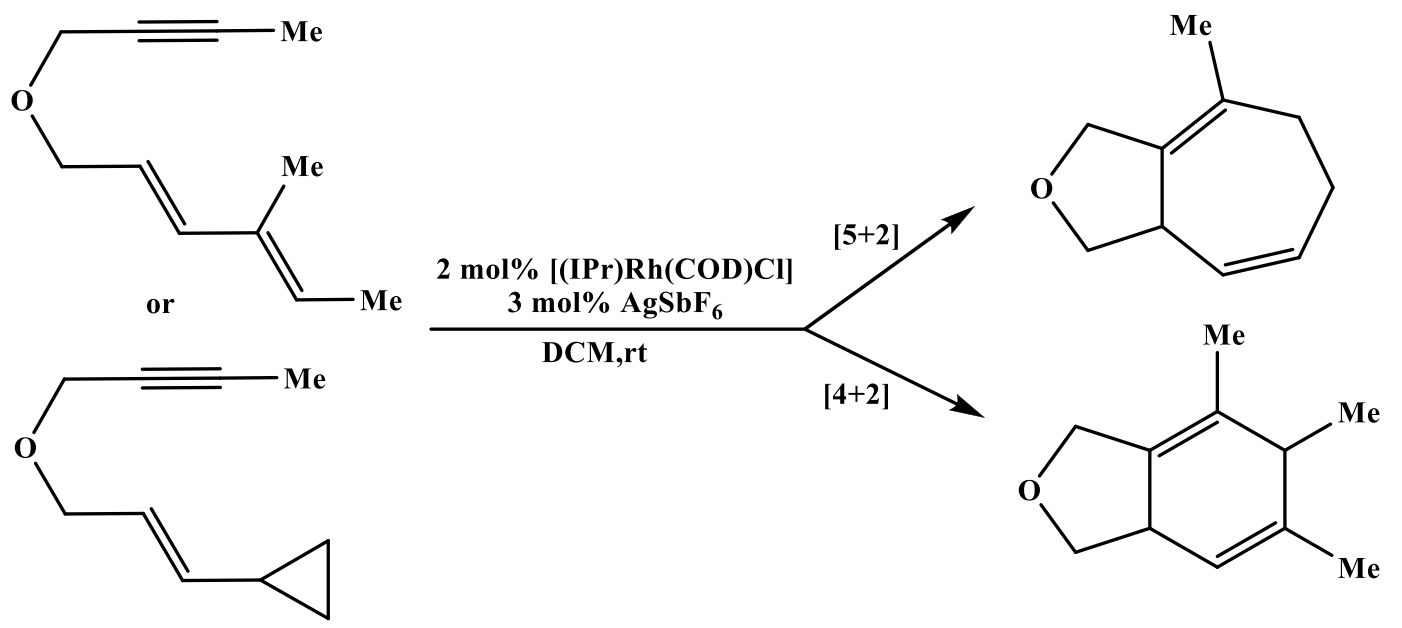

Scheme 51 Synthesis of bicyclo[5.3.0]nonadiene and bicyclo[4.3.0]octadiene derivatives 


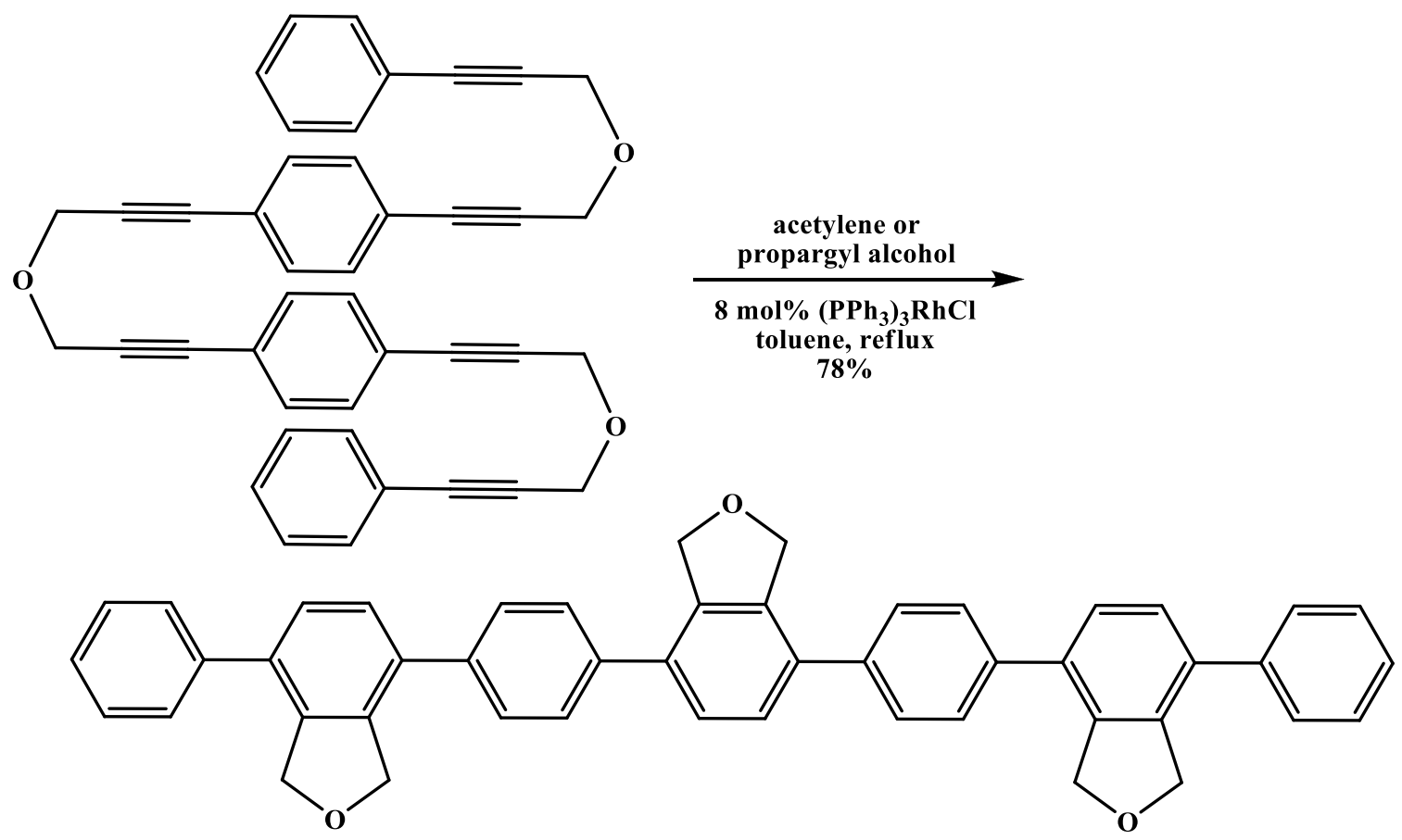

Scheme 52 Synthesis of oligo-p-phenylenes

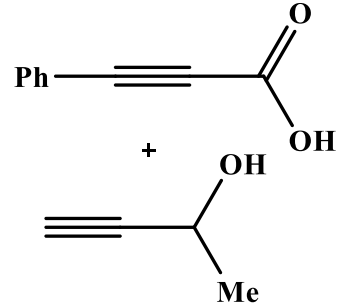

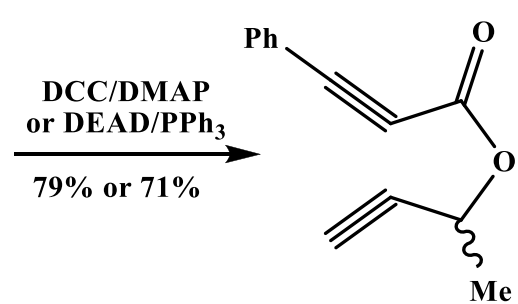

Scheme 53 Synthesis of 3-methyl-7-phenylisobenzofuran-1(3H)-one

the reactions were performed in the presence of $5 \mathrm{~mol} \%$ of Wilkinson's catalyst and acetylene gas in toluene [312].

A model benzofuran unit of diazonaniide $A$ was constructed by an intramolecular rhodium carbenoid aromatic carbon-hydrogen insertion reactions. The 2-bromophenol was easily transformed into diazoester (Scheme 54). The decomposition of diazoester was complex in the presence of rhodium(II) catalyst, and the benzofuranone was formed in only $20 \%$ yield. Subsequent C-acylation of benzofuranone for the preparation of oxazole ring was straightforward. The benzofuranone was obtained in $68 \%$ yield when ethyl chloroformate was reacted in the presence of 4-dimethylaminopyridine [314].

The viability of spirocyclopropene intermediate in the cycloaddition of dione to phenylacetylene in the presence of various chiral rhodium(II) complex catalysts, was reported by Muller [315], who rationalized that the lack of enantioinduction was an evidence for the intermediacy of compound.
Since both possible isomers of spirocyclopropene intermediate were meso-compounds, thermal rearrangement of the latter into furan synthesized a racemate, while the pathway via direct synthesis of rhodium(II)-carbenoid afforded enantiomerically enriched product. In contrast, previously it was reported that the rearrangement of achiral cyclopropenecarboxylates may also proceed enantioselectively in the presence of optically active rhodium(II) complexes [316]. Therefore, the absence of enantiomeric induction (Scheme 55) was not taken as unambiguous evidence for the involvement of cyclopropene intermediate and was simply a result of inefficacy of the chiral catalyst in this particular conversion [317, 318].

\subsection{Samarium assisted synthesis}

Armstrong and Du [319] reported a milder method for the preparation of solid-supported benzofurans via 


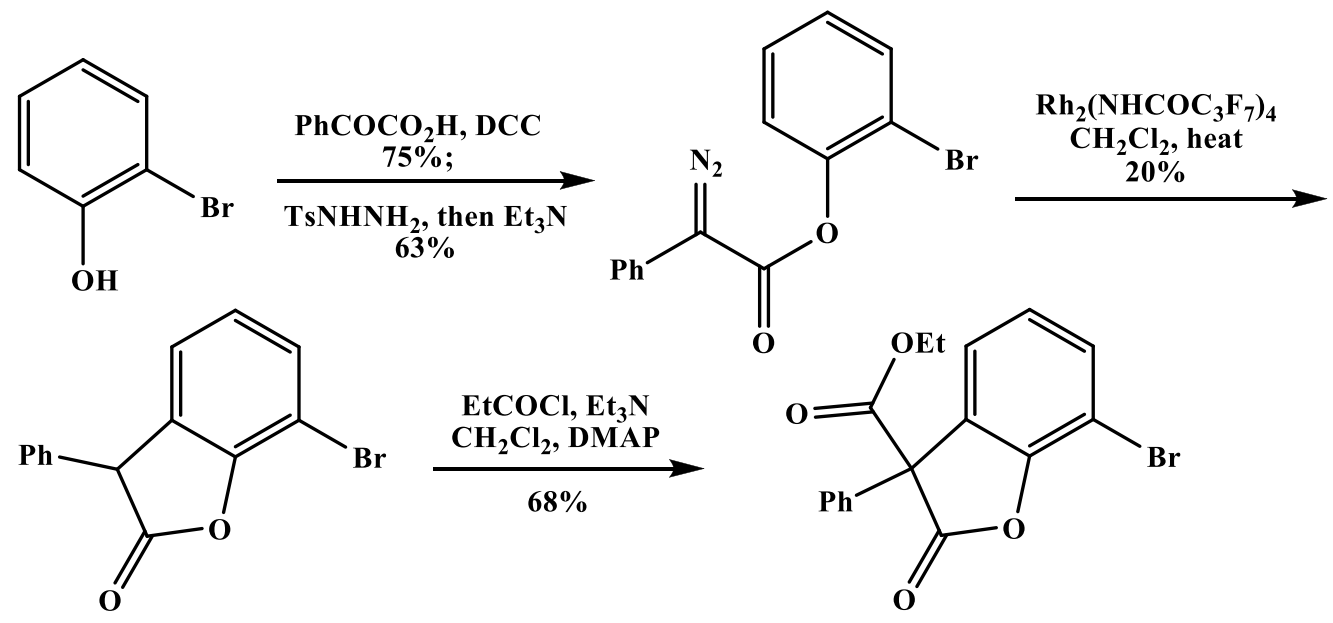

Scheme 54 Synthesis of ethyl 7-bromo-2-oxo-3-phenyl-2,3-dihydrobenzofuran-3-carboxylate

Scheme 55 Synthesis of 2,6-diphenyl-6,7-dihydrobenzofuran-4(5H)-one<smiles>O=C1CC(c2ccccc2)CC(=O)C1=[W]</smiles>

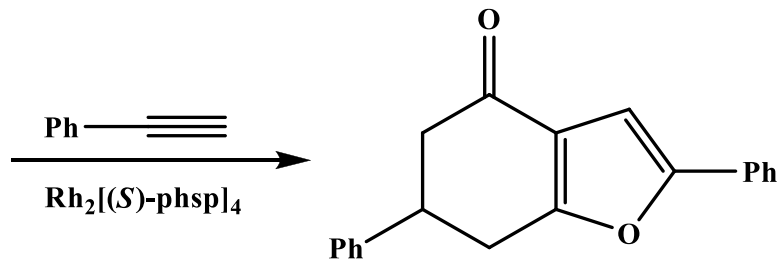<smiles>[R1]C1([R1])COc2c(OC)cc(C(N)=O)cc21</smiles>

Scheme 56 Synthesis of benzofurans

Scheme 57 Synthesis of 2-methyl-4,5,6,7-tetrahydrobenzofuran

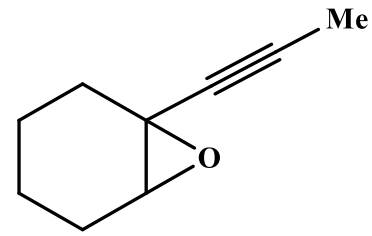<smiles>[X]c1cc2c(o1)CCCC2</smiles>

samarium iodide assisted radical cyclization (Scheme 56) [320].

\subsection{Silver assisted synthesis}

Pale and co-workers [321] synthesized furans by a Bronsted acid and silver(I)-catalyzed rearrangement of epoxyalkyne. The reaction involved the opening of epoxide with an alcohol in the presence of $p$-toluenesulfonic acid catalyst. The formed $\alpha$-alkoxy- $\beta$-alkynols were reacted with Ag ions to provide a silver(I)-containing oxacyclic cation which provided furan derivatives finally (Scheme 57) [322].

The $o$-alkynylbenzoic acids were reacted for the synthesis of isocoumarins and/or alkylidenebenzofuranones in the presence of Ag catalyst (Scheme 58). The silver powder in dimethylformamide (warm) was proved to be the most 
selective conditions which favored the 5-exo-dig cyclization. Bellina et al. [323] examined different catalysts for the cyclizatio of o-alkynylbenzoic acids; they found that silver nitrate favored the 6-endo approach (as Pd catalysts did) whereas silver promoted the synthesis of phthalides [324, 325].

Chiral dienes were synthesized efficiently by silver carbonate-catalyzed cyclization. The chiral dienes acted as key elements either for the synthesis of nagilactones or for a Diels-Alder approach to kaura-9(11)-16-dien-19-oic acid (Scheme 59) [324, 326, 327].

Intramolecular addition-cyclization reactions of ynone in the presence of Ag salts catalyst were reported in a few cases only. The aurones, a subclass of flavonoids, were prepared which contributed to the pigmentation of fruits and flowers and possess a number of pharmacological properties [328]. The 3-aryl-1-[2-hydroxyaryl] prop-2-yn-1-ones underwent 5-exo-dig cyclization for the synthesis of $Z$-aurones in catalytic amounts of $\mathrm{AgNO}_{3}$ salt. When the phenol was intramolecular nucleophile, it was possible to synthesize aurones (Scheme 60) via a high and efficient producing pathway, when starting compound was cyclized in the presence of silver nitrate in catalytic amounts. The isomeric flavones were formed in only traces $[253,324]$.

For alkenyl acids, the cyclization depends on the substitution and the chain length. This protocol offered one of the simplest procedures to produce lactones or cyclic ethers in good yields. This same reaction was also successfully employed to $o$-allylphenols. Here, Ag perchlorate in toluene was a better catalyst than Ag triflate [324, 329] (Scheme 61).

An intramolecular cyclization of phenol derivatives with a cadmium-carbon double bond on a side chain provided dihydrobenzofurans under the catalysis of Ag salts (Scheme 62). The nature of Ag-olefin complex affected the catalytic activity and was influenced by the distance between it and the Ag atom and the coordination ability of the counteranion [330]. Thus, a Ag cation bearing $\mathrm{PF}_{6}{ }^{-}$or $\mathrm{BF}_{4}{ }^{-}$as a counteranion, was strongly coordinated
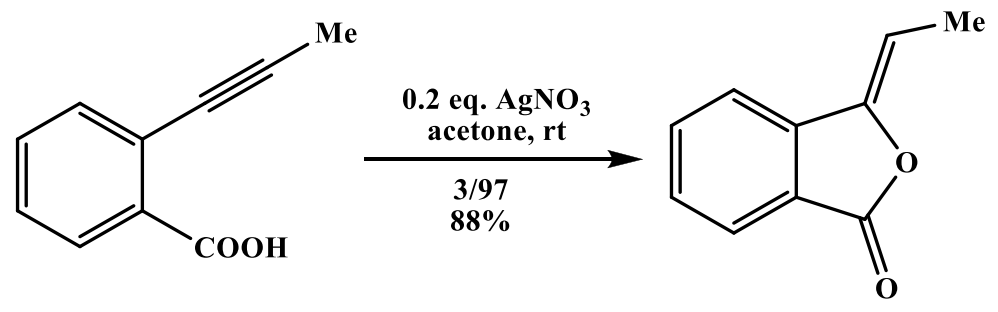<smiles>Cc1cc2ccccc2c(=O)o1</smiles>

Scheme 58 Synthesis of alkylidenebenzofuranones and/or isocoumarins

Scheme 59 Synthesis of $(5 R, 7 \mathrm{a} R)$-5-hydroxy-4,7a-dimethyl-3-methylene-5,6,7,7atetrahydroisobenzofuran$1(3 H)$-one<smiles>C#CC1=C(C)[C@H](O)CC[C@]1(C)C(=O)O</smiles>

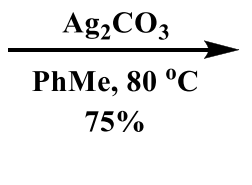<smiles>C=C1OC(=O)[C@]2(C)CC[C@@H](O)C(C)=C12</smiles>

O<smiles>Cc1ccc(/C=C2\Oc3cc(C)ccc3C2=O)cc1</smiles>

Scheme 60 Synthesis of (Z)-6-methyl-2-(4-methylbenzylidene)benzofuran-3(2H)-one 
Scheme 61 Synthesis of 2-methyl-2,3-dihydrobenzofuran<smiles>C=CCc1ccccc1O</smiles><smiles>CC1Cc2ccccc2O1</smiles><smiles>C=CCc1ccccc1O</smiles><smiles>CC1Cc2ccccc2O1</smiles>

Scheme 62 Synthesis of dihydrobenzofurans<smiles>CC1=CC(C(C)(C)C(=O)O)CCC1</smiles>

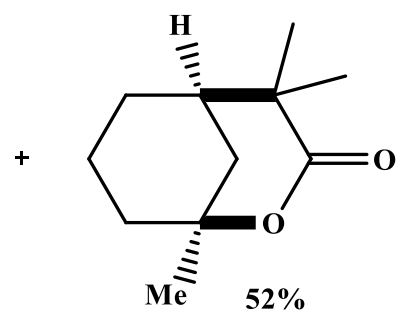

Scheme 63 Synthesis of lactones or cyclic ethers

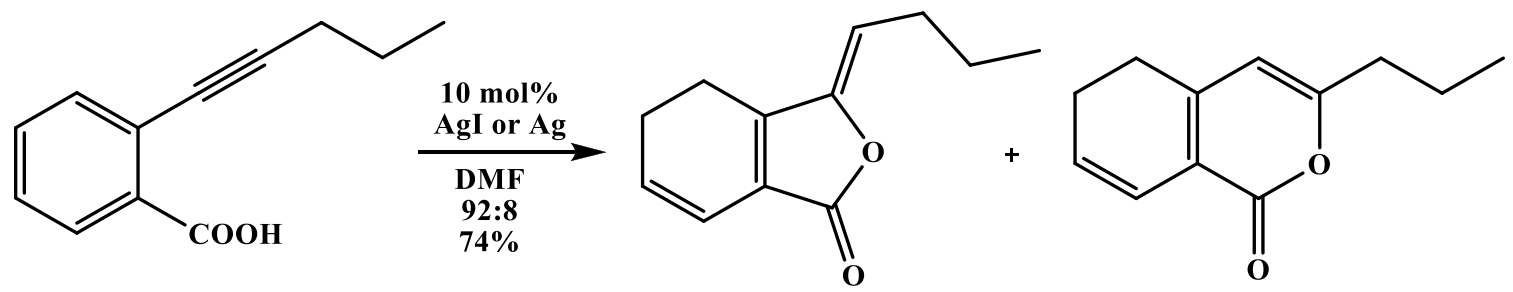

Scheme 64 Synthesis of (Z)-3-butylidene-4,5-dihydroisobenzofuran-1(3H)-one and 3-propyl-5,6-dihydro-1H-isochromen-1-one

by cadmium-carbon double bond and oxygen atom of phenol derivatives and promoted no reaction. But the coordination of silver(l) by phenolic oxygen weakens the coordination ability of $\mathrm{OTf}^{-}$and $\mathrm{ClO}_{4}{ }^{-}$and promoted the reaction efficiently [253].

Intramolecular additions of carboxyl or hydroxyl groups to inert olefins in the presence of $\mathrm{Ag}(\mathrm{I})$ triflate catalyst in 1,2-dicholoethylene was one of the newest and simplest protocols to synthesize lactones or cyclic ethers (Scheme 63) employing Ag-assisted chemistry [331]. The mechanism has proposed that the $\mathrm{Ag}(\mathrm{I})$ ion binds and activates the double bond to produce the complex, which was attacked by the oxygen-nucleophile on the opposite face. This provided an intermediate having newly formed $\mathrm{C}-\mathrm{O}$ bond present trans to the $\mathrm{Ag}-\mathrm{C}$ bond. Subsequently, proton transfer resulted in the regeneration of $\mathrm{Ag}(\mathrm{l})$ catalyst and the formation of product [253].

Many well stereodefined five-membered lactones were isolated from natural sources, and exhibit various pharmacological properties. Therefore, their preparation has attracted the attention of chemists, and many organometallic protocols have been developed utilizing $\mathrm{Ag}$ and other metals [332]. For example, the natural product ligustilide was obtained in excellent stereo- and regioselectivities and good yield by the cyclization of alkynoic acid (Scheme 64) in the presence of catalytic amounts of silver or silver iodide [333]. A reaction sequence involving silver(I)-catalyzed lactonization of the alkyne as a key step provided lissoclinolide, an antibiotic butenolide, in a stereoselective manner [334]. The same protocol was applied for the synthesis of ligustilide starting from a structurally close alkyne [253, 335].

On the basis of substrate, the higher pyranone/furanone ratios were reported either with silver iodide, with silver in dimethylformamide and high dilutions $[336,337]$ or with silver carbonate in dimethylformamide (Scheme 65) [253, 338].

Marshall et al. [339-341] reported many examples of $a$-allenic alcohol stereospecific cyclizations. Cyclization of secondary alcohol was favored with $a, a^{\prime}$-allenic diols, 


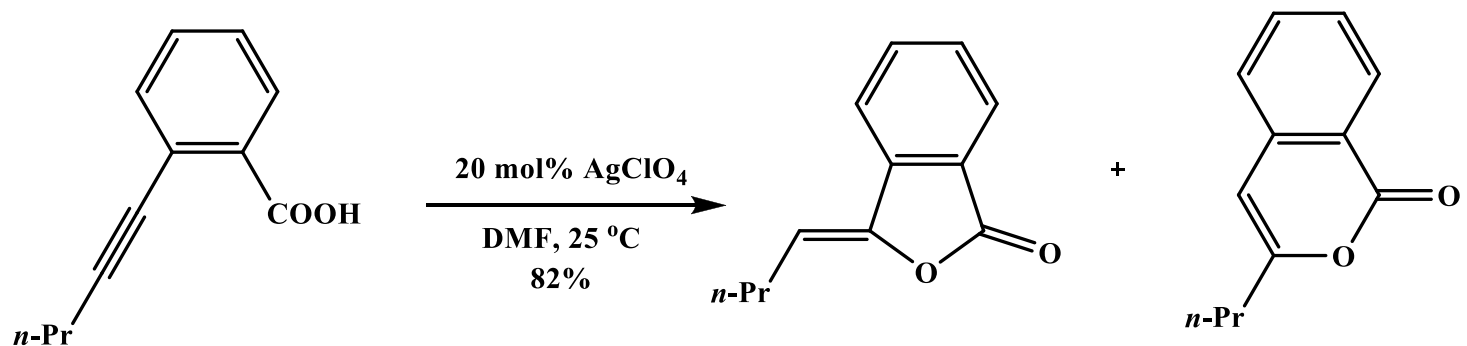

Scheme 65 Synthesis of furanone and pyranone

Scheme 66 Synthesis of $((2 R, 7 a R)-2-$ methyl-2,4,5,6,7,7ahexahydrobenzofuran-2-yl) methanol
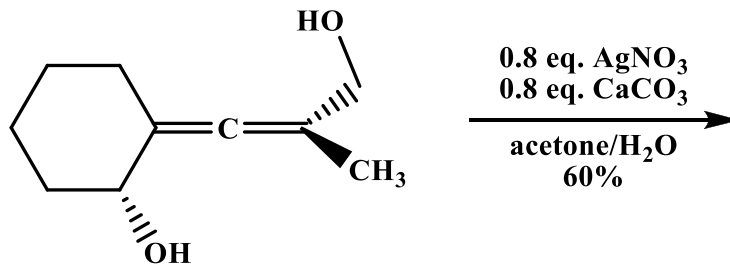<smiles>C[C@]1(CO)C=C2CCCC[C@H]2O1</smiles>

Scheme 67 Synthesis of 2-chloro-2,3,6,7-tetrahydrobenzofuran-4(5H)-one<smiles>C=CC(C)C1CCC2=C(CC(Cl)O2)C1=O</smiles><smiles>CC(=O)c1ccccc1C(C)=O</smiles><smiles>ClC1C=CCCC1</smiles>

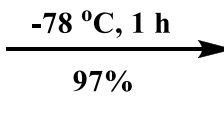<smiles>C[C@]1([C@H]2C=CCCC2)OC(=O)c2ccccc21</smiles>

Scheme 68 Synthesis of (S)-3-((R)-cyclohex-2-enyl)-3-methylisobenzofuran-1(3H)-one

possibly due to the preferential complexation of $\mathrm{Ag}^{+}$ at the less congested end of the allenyl $\pi$-system [253] (Scheme 66).

The 1,3-dicarbonyl compound was oxidized with $\mathrm{Ag}(\mathrm{I})$ metal to produce the $a$-oxoalkyl radical which attacked the olefin to provide the radical. This nucleophilic adduct underwent oxidation with $\mathrm{Ag}(\mathrm{I})$ to afford a carbonium ion, which was cyclized to dihydrofuran. This strategy was employed for the total synthesis of the natural product $a$-clausenan [253, 342] (Scheme 67).

\subsection{Zinc assisted synthesis}

This reaction provided an excellent chemoselectivity when two active groups were involved. The allylic $\mathrm{ZnCl}_{2}$ was reacted with 4-acetyl-benzoic acid methyl ester to afford the only single products in $95-96 \%$ yields. The 2-acetyl-benzoic acid methyl ester was treated with allylic $\mathrm{ZnCl}_{2}$ to synthesize the lactone in an excellent diastereoselectivity as well as $97 \%$ yield (Scheme 68 ) [343]. 

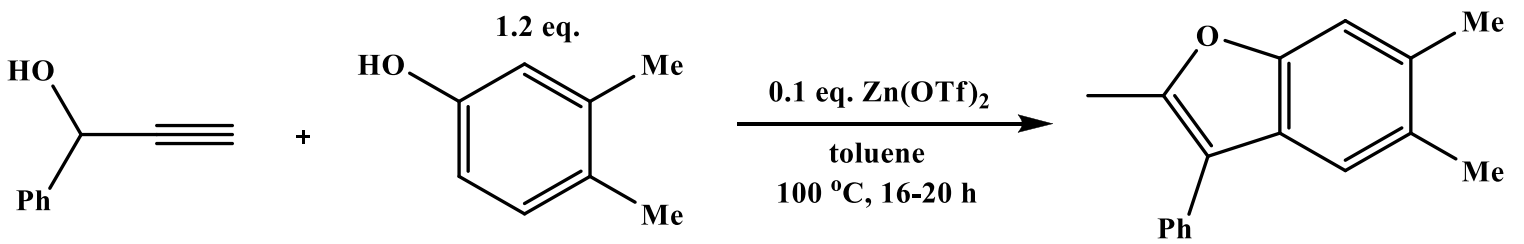

Scheme 69 Synthesis of 2,5,6-trimethyl-3-phenylbenzofuran

Various benzofuran products with different structures were obtained by $\mathrm{Zn}(\mathrm{OTf})_{2}$ catalyzed cyclization of propargyl alcohols with phenols and anilines at $100^{\circ} \mathrm{C}$ in toluene without additive. The oxazoles were formed by the cyclization of propargyl alcohols and amides [344] (Scheme 69).

\section{Conclusion}

The efficient and chemoselective synthesis of heterocycles by this technique has appeared as an important tool. This review shows a highly dynamic research field and the employment of metal and non-metal catalysts in organic synthesis. Several strategies have been pointed out in the past few years, to meet more sustainable, efficient and environmentally benign chemical products and procedures. The catalytic strategies have been focus of intense research because they avoid the use of toxic reagents. Among these catalytic strategies, highly rewarding and an important method in heterocycles synthesis is metal and non-metal catalyzed synthesis.

Funding There is no funding for this study.

\section{Compliance with ethical standards}

Conflict of interest The authors declare that they have no conflict of interest.

\section{References}

1. Balaban AT, Oniciu DC, Katritzky AR (2004) Aromaticity as a cornerstone in heterocyclic chemistry. Chem Rev 104:2777-2812

2. Kaur N (2015) Palladium-catalyzed approach to the synthesis of S-heterocycles. Catal Rev 57:478-564

3. Reddy MD, Fronczek FR, Watkins EB (2016) Rh-catalyzed, regioselective, $\mathrm{C}-\mathrm{H}$ bond activation: access to quinoline branched amines and dimers. Org Lett 18:5620-5623

4. Reddy MD, Uredi D, Watkins EB (2018) A general method for the metal-free, regioselective, remote $\mathrm{C}-\mathrm{H}$ halogenation of 8-substituted quinolines. Chem Sci 9:1782-1788

5. Martins MAP, Cunico W, Pereira CMP, Flores AFC, Bonacorso HG, Zanatta N (2004) 4-Alkoxy-1,1,1-trichloro-3-alken-2-ones: preparation and applications in heterocyclic synthesis. Curr Org Synth 1:391-403

\section{SN Applied Sciences}

6. Majumdar P, Pati A, Patra M, Behera RK, Behera AK (2014) Acid hydrazides, potent reagents for synthesis of oxygen-, nitrogen-, and/or sulfur-containing heterocyclic rings. Chem Rev 114:2942-2977

7. Reddy MD, Kobori H, Mori T, Wu J, Kawagishi H, Watkins EB (2017) Gram-scale, stereoselective synthesis and biological evaluation of (+)-armillariol C. J Nat Prod 80:2561-2565

8. Reddy CR, Dilipkumar U, Reddy MD (2014) Novel [4+2]-benzannulation to access substituted benzenes, polycyclic aromatic and benzene-fused heteroaromatic compounds. Org Lett 16:3792-3795

9. Domling A (2006) Recent developments in isocyanide based multi-component reactions in applied chemistry. Chem Rev 106:17-89

10. Kaur N (2019) Applications of palladium dibenzylideneacetone as catalyst in the synthesis of five-membered $N$-heterocycles. Synth Commun 49:1205-1230

11. Kaur N (2019) Copper catalyzed synthesis of seven and higher-membered heterocycles. Synth Commun 49:879-916

12. Kaur N (2019) lonic liquid assisted synthesis of S-heterocycles. Phosphorus Sulfur Silicon Relat Elem 194:165-185

13. Kaur N (2019) Nickel catalysis: six membered heterocycle syntheses. Synth Commun 49:1103-1133

14. Kaur N (2019) Seven-membered $N$-heterocycles: metal and non-metal assisted synthesis. Synth Commun 49:987-1030

15. Kaur N, Bhardwaj P, Devi M, Verma Y, Grewal P (2019) Synthesis of five-membered $\mathrm{O}, \mathrm{N}$-heterocycles using metal and non-metal. Synth Commun 49:1345-1384

16. Kaur N (2019) Synthetic routes to seven and higher membered S-heterocycles by use of metal and nonmetal catalyzed reactions. Phosphorus Sulfur Silicone Relat Elem 194:186-209

17. Kaur N (2019) Synthesis of six-membered N-heterocycles using ruthenium catalysts. Catal Lett 14:1513-1539

18. Reddy CR, Reddy MD (2014) A metal-free tandem C-C/C-O bond formation approach to diversely functionalized tetrasubstituted furans. J Org Chem 79:106-116

19. Kaur N (2015) Benign approaches for the microwave-assisted synthesis of five-membered 1,2-N,N-heterocycles. J Heterocycl Chem 52:953-973

20. Kaur N (2017) Methods for metal and non-metal catalyzed synthesis of six-membered oxygen containing poly-heterocycles. Curr Org Synth 14:531-556

21. Kaur N (2017) Photochemical reactions: synthesis of sixmembered $N$-heterocycles. Curr Org Synth 14:972-998

22. Kaur N (2017) lonic liquids: promising but challenging solvents for the synthesis of $\mathrm{N}$-heterocycles. Mini Rev Org Chem 14:3-23

23. Kaur N (2016) Metal catalysts for the formation of six-membered $\mathrm{N}$-polyheterocycles. Synth React Inorg Met Org NanoMet Chem 46:983-1020

24. Kaur N (2017) Applications of gold catalysts for the synthesis of five-membered O-heterocycles. Inorg Nano-Met Chem 47:163-187 
25. Orru RVA, de Greef M (2003) Recent advances in solution-phase multi-component methodology for the synthesis of heterocyclic compounds. Synthesis 10:1471-1499

26. Kaur N (2018) Ruthenium catalysis in six-membered O-heterocycles synthesis. Synth Commun 48:1551-1587

27. Kaur N (2018) Green synthesis of three to five-membered O-heterocycles using ionic liquids. Synth Commun 48:1588-1613

28. Kaur N (2018) Ultrasound-assisted green synthesis of five-membered $O$ - and S-heterocycles. Synth Commun 48:1715-1738

29. Kaur N (2018) Photochemical mediated reactions in five-membered O-heterocycles synthesis. Synth Commun 48:2119-2149

30. Kaur N (2018) Mercury-catalyzed synthesis of heterocycles. Synth Commun 48:2715-2749

31. Kaur N (2018) Photochemical irradiation: seven and higher membered O-heterocycles. Synth Commun 48:2935-2964

32. Kaur N (2018) Synthesis of seven and higher membered nitrogen containing heterocycles using photochemical irradiation. Synth Commun 48:2815-2849

33. Kaur N (2018) Ruthenium catalyzed synthesis of five-membered O-heterocycles. Inorg Chem Commun 99:82-107

34. Reddy MD, Watkins EB (2015) Palladium-catalyzed direct arylation of $\mathrm{C}\left(\mathrm{sp}^{3}\right)-\mathrm{H}$ bonds of $a$-cyano aliphatic amides. J Org Chem 80:11447-11459

35. Kaur N (2014) Palladium-catalyzed approach to the synthesis of five-membered $\mathrm{O}$-heterocycles. Inorg Chem Commun 49:86-119

36. Kaur N, Kishore D (2014) Nitrogen-containing six-membered heterocycles: solid-phase synthesis. Synth Commun 44:1173-1211

37. Kaur N, Kishore D (2014) Solid-phase synthetic approach toward the synthesis of oxygen containing heterocycles. Synth Commun 44:1019-1042

38. Kaur N (2014) Microwave-assisted synthesis of five membered O-heterocycles. Synth Commun 44:3483-3508

39. Kaur N (2014) Microwave-assisted synthesis of five membered $\mathrm{O}, \mathrm{N}$-heterocycles. Synth Commun 44:3509-3537

40. Kaur N (2014) Microwave-assisted synthesis of five membered $\mathrm{O}, \mathrm{N}, \mathrm{N}$-heterocycles. Synth Commun 44:3229-3247

41. Kaur N (2018) Synthesis of six and seven-membered heterocycles under ultrasound irradiation. Synth Commun 48:1235-1258

42. Kaur N (2018) Photochemical reactions as key steps in five-membered $\mathrm{N}$-heterocycles synthesis. Synth Commun 48:1259-1284

43. Kaur N (2018) Solid-phase synthesis of sulfur containing heterocycles. J Sulfur Chem 39:544-577

44. Kaur N (2015) Metal catalysts: applications in higher membered $\mathrm{N}$-heterocycles synthesis. J Iran Chem Soc 12:9-45

45. Kaur N (2015) Insight into microwave-assisted synthesis of benzo derivatives of five membered $\mathrm{N}, \mathrm{N}$-heterocycles. Synth Commun 45:1269-1300

46. Kaur N (2015) Synthesis of fused five-membered N,N-heterocycles using microwave irradiation. Synth Commun 45:1379-1410

47. Kaur N (2014) Microwave-assisted synthesis of seven membered S-heterocycles. Synth Commun 44:3201-3228

48. Kaur N (2015) Six membered $N$-heterocycles: microwaveassisted synthesis. Synth Commun 45:1-34

49. Kaur N (2015) Polycyclic six membered $N$-heterocycles: microwave-assisted synthesis. Synth Commun 45:35-69

50. Kaur N (2018) Copper catalysts in the synthesis of five-membered $N$-polyheterocycles. Curr Org Synth 15:940-971

51. Kaur N (2018) Recent developments in the synthesis of nitrogen containing five-membered polyheterocycles using rhodium catalysts. Synth Commun 48:2457-2474
52. Kaur N (2015) Microwave-assisted synthesis: fused five membered $N$-heterocycles. Synth Commun 45:789-823

53. Kaur N (2015) Six membered heterocycles with three and four $\mathrm{N}$-heteroatoms: microwave-assisted synthesis. Synth Commun 45:151-172

54. Kaur N (2015) Application of microwave-assisted synthesis in the synthesis of fused six-membered heterocycles with $\mathrm{N}$-heteroatom. Synth Commun 45:173-201

55. Kaur N (2015) Microwave-assisted synthesis of fused polycyclic six membered $N$-heterocycles. Synth Commun 45:273-299

56. Kaur N (2015) Review of microwave-assisted synthesis of benzo fused six-membered $N, N$-heterocycles. Synth Commun 45:300-330

57. Kaur N, Kishore D (2014) Synthetic strategies applicable in the synthesis of privileged scaffold: 1,4-benzodiazepine. Synth Commun 44:1375-1413

58. Kaur N (2015) Environmentally benign synthesis of five membered $1,3-\mathrm{N}, \mathrm{N}$-heterocycles by microwave irradiation. Synth Commun 45:909-943

59. Kaur N (2015) Advances in microwave-assisted synthesis for five membered $\mathrm{N}$-heterocycles synthesis. Synth Commun 45:432-457

60. Kaur N (2014) Microwave-assisted synthesis of five membered S-heterocycles. J Iran Chem Soc 11:523-564

61. Kaur N (2015) Review on the synthesis of six membered $\mathrm{N}, \mathrm{N}$-heterocycles by microwave irradiation. Synth Commun 45:1145-1182

62. Kaur N (2015) Greener and expeditious synthesis of fused six-membered $\mathrm{N}, \mathrm{N}$-heterocycles using microwave irradiation. Synth Commun 45:1493-1519

63. Kaur N (2015) Applications of microwaves in the synthesis of polycyclic six membered $\mathrm{N}, \mathrm{N}$-heterocycles. Synth Commun 45:1599-1631

64. Kaur N (2015) Synthesis of five-membered N, N, N- and N, N, N $\mathrm{N}$-heterocyclic compounds: applications of microwaves. Synth Commun 45:1711-1742

65. Kaur N (2019) Palladium acetate and phosphine assisted synthesis of five-membered $\mathrm{N}$-heterocycles. Synth Commun 49:483-514

66. Kaur N (2019) Application of silver-promoted reactions in the synthesis of five-membered $\mathrm{O}$-heterocycles. Synth Commun 49:743-789

67. Kaur N (2019) Synthesis of seven and higher-membered heterocycles using ruthenium catalysts. Synth Commun 49:617-661

68. Patil NT, Yamamoto Y (2008) Coinage metal-assisted synthesis of heterocycles. Chem Rev 108:3395-3442

69. Kaur N (2015) Role of microwaves in the synthesis of fused five membered heterocycles with three $\mathrm{N}$-heteroatoms. Synth Commun 45:403-431

70. Kaur N (2015) Recent impact of microwave-assisted synthesis on benzo derivatives of five membered $\mathrm{N}$-heterocycles. Synth Commun 45:539-568

71. Kaur N, Kishore D (2014) Microwave-assisted synthesis of seven and higher membered $\mathrm{N}$-heterocycles. Synth Commun 44:2577-2614

72. Kaur N, Kishore D (2014) Microwave-assisted synthesis of sixmembered S-heterocycles. Synth Commun 44:2615-2644

73. Kaur N, Kishore D (2014) Microwave-assisted synthesis of seven and higher membered $O$-heterocycles. Synth Commun 44:2739-2755

74. Alberico D, Scott ME, Lautens M (2007) Aryl bond formation by transition-metal-catalyzed direct arylation. Chem Rev 107:174-238

75. Kaur N (2017) Gold catalysts in the synthesis of five-membered $\mathrm{N}$-heterocycles. Curr Organocatal 4:122-154 
76. Kaur N, Bhardwaj P, Devi M, Verma Y, Grewal P (2019) Photochemical reactions in five and six-membered polyheterocycles synthesis. Synth Commun 49:2281-2318

77. Dick AR, Sanford MS (2006) Transition metal catalyzed oxidative functionalization of carbon-hydrogen bonds. Tetrahedron 62:2439-2463

78. Kaur N (2015) Palladium catalysts: synthesis of five-membered $\mathrm{N}$-heterocycles fused with other heterocycles. Catal. Rev. 57:1-78

79. Kaur N, Kishore D (2014) Microwave-assisted synthesis of six membered O,O-heterocycles. Synth Commun 44:3082-3111

80. Kaur N, Kishore D (2014) Microwave-assisted synthesis of six membered O-heterocycles. Synth Commun 44:3047-3081

81. Nakamura YY (2004) Transition-metal-catalyzed reactions in heterocyclic synthesis. Chem Rev 104:2127-2198

82. Kaur N, Verma Y, Grewal P, Bhardwaj P, Devi M (2019) Application of titanium catalysts for the syntheses of heterocycles. Synth Commun 49:1847-1894

83. Kaur N (2019) lonic liquid: an efficient and recyclable medium for the synthesis of fused six-membered oxygen heterocycles. Synth Commun 49:1679-1707

84. Kaur N (2019) Multiple nitrogen-containing heterocycles: metal and non-metal assisted synthesis. Synth Commun 49:1633-1658

85. Kaur N, Grewal P, Bhardwaj P, Devi M, Verma Y (2019) Nickelcatalyzed synthesis of five-membered heterocycles. Synth Commun 49:1543-1577

86. Kaur N (2019) Gold and silver assisted synthesis of five-membered oxygen and nitrogen containing heterocycles. Synth Commun 49:1459-1485

87. Kaur N (2018) Synthesis of six- and seven-membered and larger heterocylces using Au and Ag catalysts. Inorg Nano-Met Chem 48:541-568

88. Zeni G, Larock RC (2006) Synthesis of heterocycles via palladium-catalyzed oxidative addition. Chem Rev 106:4644-4680

89. Jimenez-Gonzalez L, Garcia-Munoz S, Alvarez-Corral M, MunozDorado M, Rodriguez-Garcia I (2006) Silver-catalyzed asymmetric synthesis of 2,3-dihydrobenzofurans: a new chiral synthesis of pterocarpans. Chem Eur J 12:8762-8779

90. Li Z, He C (2006) Recent advances in silver-catalyzed nitrene, carbene, and silylene-transfer reactions. Eur J Org Chem 19:4313-4322

91. Wang Z, Gu JZ, Jing HW, Liang YM (2009) Novel one-pot synthesis of 3-phenylnaphtho[2,3-b]furan and 3-phenylbenzofurans under microwave irradiation and solvent-free conditions. Synth Commun 39:4079-4087

92. Das A, Kulkarni A, Torok B (2012) Environmentally benign synthesis of heterocyclic compounds by combined microwaveassisted heterogeneous catalytic approaches. Green Chem 14:17-34

93. Martino E, Bartalena L, Bogazzi F, Braverman LE (2001) The effects of amiodarone on the thyroid. Endocr Rev 22:240-254

94. Zareba KM (2006) Dronedarone: a new antiarrhythmic agent. Drugs Today 42:75-86

95. Zeni G, Larock RC (2004) Synthesis of heterocycles via palladium $\pi$-olefin and $\pi$-alkyne chemistry. Chem Rev 104:2285-2310

96. Varma RS, Kumar D, Liesen PJ (1998) Solid state synthesis of 2-aroylbenzo[b]furans, 1,3-thiazoles and 3-aryl-5,6-dihydroimidazo[2,1-b][1,3]thiazoles from $a$-tosyloxyketones using microwave irradiation. J Chem Soc Perkin Trans 1 24:4093-4096

97. Varma RS (1999) Solvent-free synthesis of heterocyclic compounds using microwaves. J Heterocycl Chem 36:1565-1571

98. Wada M, Fukuma T, Morioka M, Takahashi T, Miyoshi N (1997) A novel aqueous Barbier-Grignard-type allylation of aldehydes in a $\mathrm{Mg} / \mathrm{BiCl}_{3}$ bimetal system. Tetrahedron Lett 38:8045-8048
99. Wada M, Honna M, Kuramoto Y, Miyoshi N (1997) A Grignard type addition of allyl unit to carbonyl compounds containing a carboxyl group by using $\mathrm{BiCl}_{3}-\mathrm{Zn}(0)$-allyl bromide. Bull Chem Soc Jpn 70:2265-2267

100. Beck JJ, Chou S-C (2007) The structural diversity of phthalides from the apiaceae. J Nat Prod 70:891-900

101. Salvador JAR, Pinto RMA, Silvestreb SM (2009) Recent advances of bismuth(III) salts in organic chemistry: application to the synthesis of heterocycles of pharmaceutical interest. Curr Org Synth 6:426-470

102. Shang YJ, Wang C, He XW, Ju K, Zhang M, Yu SY, Wu JP (2010) DMAP-catalyzed cascade reaction: one-pot synthesis of benzofurans in water. Tetrahedron 66:9629-9633

103. Kumaraswamy G, Ramakrishna G, Raju R, Padmaja M (2010) An expedient synthesis of enantioenriched substituted (2-benzofuryl)arylcarbinols via tandem Rap-Stoermer and asymmetric transfer hydrogenation reactions. Tetrahedron 66:9814-9818

104. Liegault B, Lapointe D, Caron L, Vlassova A, Fagnou K (2009) Establishment of broadly applicable reaction conditions for the palladium-catalyzed direct arylation of heteroatom-containing aromatic compounds. J Org Chem 74:1826-1834

105. Chaudhary S, Harding WW (2011) Synthesis of C-homoaporphines via microwave-assisted direct arylation. Tetrahedron 67:569-575

106. Gorelsky SI, Lapointe D, Fagnou K (2008) Analysis of the concerted metalation-deprotonation mechanism in palladiumcatalyzed direct arylation across a broad range of aromatic substrates. J Am Chem Soc 130:10848-10849

107. Xing XL, Wu JL, Luo JL, Dai W-M (2006) C-N bond-linked conjugates of dibenz $[b, f][1,4]$ oxazepines with 2-oxindole. Synlett 13:2099-2103

108. Miki K, Yokoi T, Nishino F, Kato Y, Washitake Y, Ohe K, Uemura $S$ (2004) Catalytic cyclopropanation of alkenes via (2-furyl)carbene complexes from 1-benzoyl-cis-1-buten-3-yne with transition metal compounds. J Org Chem 69:1557-1564

109. Miki K, Nishino F, Ohe K, Uemura S (2002) Novel approach for catalytic cyclopropanation of alkenes via (2-furyl)carbene complexes from 1-benzoyl-cis-1-buten-3-yne. J Am Chem Soc 124:5260-5261

110. Miki K, Uemura S, Ohe K (2005) Transition metal-catalyzed reactions using alkynes as precursors of carbene and vinylidene complexes. Chem Lett 34:1068-1073

111. Ohe K (2007) Transition metal-catalyzed and -promoted reactions via carbene and vinylidene complexes generated from alkynes. Bull Korean Chem Soc 28:2153-2161

112. Reich NW, Yang C-G, Shi Z, He C (2006) Gold(I)-catalyzed synthesis of dihydrobenzofurans from aryl allyl ethers. Synlett 8:1278-1280

113. Nguyen RV, Yao X-Q, Li C-J (2006) Highly efficient gold-catalyzed atom-economical annulation of phenols with dienes. Org Lett 8:2397-2399

114. Li Z, Brouwer C, He C (2008) Gold-catalyzed organic transformations. Chem Rev 108:3239-3265

115. Harkat H, Weibel J-M, Pale P (2006) A mild access to $\gamma$ - or $\delta$-alkylidene lactones through gold catalysis. Tetrahedron Lett 47:6273-6276

116. Marchal $E$, Uriac $P$, Legouin $B$, Toupet $L$, van de Weghe $P(2007)$ Cycloisomerization of $\gamma$ - and $\delta$-acetylenic acids catalyzed by gold(I) chloride. Tetrahedron 63:9979-9990

117. Uchiyama M, Ozawa H, Takuma K, Matsumoto $Y$, Yonehara M, Hiroya K, Sakamoto T (2006) Regiocontrolled intramolecular cyclizations of carboxylic acids to carbon-carbon triple bonds promoted by acid or base catalyst. Org Lett 8:5517-5520

118. Arcadi A (2008) Alternative synthetic methods through new developments in catalysis by gold. Chem Rev 108:3266-3325 
119. Hashmi ASK, Frost TM, Bats JW (2001) Gold catalysis: on the phenol synthesis. Org Lett 3:3769-3771

120. Hashmi ASK, Frost TM, Bats JW (2000) Highly selective goldcatalyzed arene synthesis. J Am Chem Soc 122:11553-11554

121. Echavarren AM, Mendez M, Munoz MP, Nevado C, MartinMatute B, Nieto-Oberhuber C, Cardenas DJ (2004) Metal cyclopropyl carbenes in the reactions of alkynes with alkenes and furans. Pure Appl Chem 76:453-463

122. Liu X, Pan Z, Shu X, Duan X, Liang $Y$ (2006) $\mathrm{Bu}_{4} \mathrm{~N}\left[\mathrm{AuCl}_{4}\right]$-catalyzed synthesis of highly substituted furans from 2-(1-alkynyl)-2alken-1-ones in ionic liquids: an air-stable and recyclable catalytic system. Synlett 12:1962-1964

123. Ambrogio I, Arcadi A, Cacchi S, Fabrizi G, Marinelli F (2007) Gold-catalyzed synthesis of 2-substituted, 2,3-disubstituted and 1,2,3-trisubstituted indoles in [bmim]BF 4 . Synlett 11:1775-1779

124. Aksin O, Krause N (2008) Gold-catalyzed synthesis of 2,5-dihydrofurans in ionic liquids. Adv Synth Catal 350:1106-1112

125. Michelet V, Toullec PY, Genet J-P (2008) Cycloisomerization of 1 , n-enynes: challenging metal-catalyzed rearrangements and mechanistic insights. Angew Chem Int Ed 47:4268-4315

126. Zhang Z, Zhu G, Tong X, Wang F, Xie X, Wang J, Jiang L (2006) Transition metal-catalyzed intramolecular enyne cyclization reaction. Curr Org Chem 10:1457-1478

127. Bruneau C (2005) Electrophilic activation and cycloisomerization of enynes: a new route to functional cyclopropanes. Angew Chem Int Ed 44:2328-2334

128. Diver ST, Giessert AJ (2004) Enyne metathesis (enyne bond reorganization). Chem Rev 104:1317-1382

129. Echavarren AM, Nevado C (2004) Non-stabilized transition metal carbenes as intermediates in intramolecular reactions of alkynes with alkenes. Chem Soc Rev 33:431-436

130. Lloyd- Jones $G$ (2003) Mechanistic aspects of transition metal catalysed 1,6-diene and 1,6-enyne cycloisomerisation reactions. Org Biomol Chem 1:215-236

131. Aubert C, Buisine O, Malacria M (2002) The behavior of 1, $\mathrm{n}$-enynes in the presence of transition metals. Chem Rev 102:813-834

132. Lopez $S$, Herrero-Gomez E, Perez-Galan P, Nieto-Oberhuber C, Echavarren AM (2006) Multifunctional catalysis of a ruthenium-grafted hydrotalcite: one-pot synthesis of quinolines from 2-aminobenzyl alcohol and various carbonyl compounds via aerobic oxidation and aldol reaction. Angew Chem Int Ed 45:6029-6032

133. Kim SM, Park JH, Choi SY, Chung YK (2007) ( $N$-Heterocyclic carbene)gold(I)-catalyzed cycloisomerization of cyclohexadienyl alkynes to tetracyclo[3.3.0.02,8.04,6]octanes. Angew Chem Int Ed 46:6172-6175

134. Witham CA, Mauleon P, Shapiro ND, Sherry BD, Toste FD (2007) Gold(I)-catalyzed oxidative rearrangements. J Am Chem Soc 129:5838-5839

135. Ricard L, Gagosz F (2007) Synthesis and reactivity of air-stable $\mathrm{N}$-heterocyclic carbene gold(I) bis(trifluoromethanesulfonyl) imidate complexes. Organometallics 26:4704-4707

136. Escribano-Cuesta A, Lopez-Carrillo V, Janssen D, Echavarren AM (2009) Gold-catalyzed reactions of 1,5- and 1,6-enynes with carbonyl compounds: cycloaddition vs. metathesis. Chem Eur J 15:5646-5650

137. Kim SM, Park JH, Kang YK, Chung YK (2009) N-Heterocyclic carbene gold $(\mathrm{I})$ catalyzed transformation of $\mathrm{N}$-tethered 1,5-bisallenes to 6,7-dimethylene-3-azabicyclo-[3.1.1] heptanes. Angew Chem Int Ed 48:4532-4535

138. Bartolome C, Ramiro Z, Perez-Galan P, Bour C, Raducan $M$, Echavarren AM, Espinet P (2008) Gold(I) complexes with hydrogen-bond supported heterocyclic carbenes as active catalysts in reactions of 1,6-enynes. Inorg Chem 47:11391-11397
139. Sromek AW, Rubina M, Gevorgyan V (2005) 1,2-Halogen migration in haloallenyl ketones: regiodivergent synthesis of halofurans. J Am Chem Soc 127:10500-10501

140. Zhou C-Y, Chan PWH, Che CM (2006) Gold(III) porphyrin-catalyzed cycloisomerization of allenones. Org Lett 8:325-328

141. Dudnik AS, Gevorgyan V (2007) Metal-catalyzed [1,2]-alkyl shift in allenyl ketones: synthesis of multisubstituted furans. Angew Chem Int Ed 46:5195-5197

142. Zhang G, Huang X, Li G, Zhang L (2008) Au-containing all-carbon 1,4-dipoles: generation and [4+2] annulation in the formation of carbo-/heterocycles. J Am Chem Soc 130:1814-1815

143. Diez-Gonzalez S, Marion N, Nolan SP (2009) N-heterocyclic carbenes in late transition metal catalysis. Chem Rev 109:3612-3676

144. Yao T, Zhang X, Larock RC (2004) $\mathrm{AuCl}_{3}$-Catalyzed synthesis of highly substituted furans from 2-(1-alkynyl)-2-alken-1-ones. J Am Chem Soc 126:11164-11165

145. Patil NT, Wu H, Yamamoto $\mathrm{Y}(2005) \mathrm{Cu}(\mathrm{I})$ catalyst in DMF: an efficient catalytic system for the synthesis of furans from 2-(1-alkynyl)-2-alken-1-ones. J Org Chem 70:4531-4534

146. Hashmi ASK, Schwarz L, Choi JH, Frost TM (2000) A new gold-catalyzed $\mathrm{C}-\mathrm{C}$ bond formation. Angew Chem Int Ed 39:2285-2288

147. Hashmi ASK, Ruppert TL, Knofel T, Bats JW (1997) C-C-bond formation by the palladium-catalyzed cycloisomerization/dimerization of terminal allenyl ketones: selectivity and mechanistic aspects. J Org Chem 62:7295-7304

148. Hashmi ASK (1995) Transition metal catalyzed dimerization of allenyl ketones. Angew Chem 107:1749-1751

149. Hashmi ASK (1995) Transition metal catalyzed dimerization of allenyl ketones. Angew Chem Int Ed Engl 34:1581-1583

150. Marshall JA, Sehon CA (1995) Synthesis of furans and 2,5-dihydrofurans by $\mathrm{Ag}(\mathrm{I})$-catalyzed isomerization of allenones, alkynyl allylic alcohols, and allenylcarbinols. J Org Chem 60:5966-5968

151. Marshall JA, Wallace EM, Coan PS (1995) Total synthesis of the pseudopterane (+)-Kallolide B. J Org Chem 60:796-797

152. Marshall JA, Wang XJ (1992) Synthesis of 2,5-furanocycles through intraannular cyclization of macrocyclic allenones. J Org Chem 57:3387-3396

153. Marshall JA, Wang XJ (1991) Synthesis of furans by silver(I)promoted cyclization of allenyl ketones and aldehydes. J Org Chem 56:960-969

154. Buzas A, Gagosz F (2006) Gold(I) catalyzed isomerization of 5-en-2-yn-1-yl acetates: an efficient access to acetoxy bicyclo[3.1.0]hexenes and 2-cycloalken-1-ones. J Am Chem Soc 128:12614-12615

155. Zhao J, Hughes CO, Toste FD (2006) Synthesis of aromatic ketones by a transition metal-catalyzed tandem sequence. J Am Chem Soc 128:7436-7437

156. Jimenez-Nunez E, Claverie CK, Nieto-Oberhuber C, Echavarren AM (2006) Prins cyclizations in Au-catalyzed reactions of enynes. Angew Chem 118:5578-5581

157. Jimenez-Nunez E, Claverie CK, Nieto-Oberhuber C, Echavarren AM (2006) Prins cyclizations in Au-catalyzed reactions of enynes. Angew Chem Int Ed 45:5452-5455

158. Seregin IV, Gevorgyan V (2006) Gold-catalyzed 1,2-migration of silicon, tin, and germanium en route to $\mathrm{C}-2$ substituted fused pyrrole-containing heterocycles. J Am Chem Soc 128:12050-12051

159. Nieto-Oberhuber C, Lopez $S$, Jimenez-Nunez E, Echavarren $A M$ (2006) The mechanistic puzzle of transition-metal-catalyzed skeletal rearrangements of enynes. Chem Eur J 12:5916-5923

160. Zhang AL (2005) Tandem Au-catalyzed 3,3-rearrangement-[2+2] cycloadditions of propargylic esters: expeditious access to highly functionalized 2,3-indoline-fused cyclobutanes. J Am Chem Soc 127:16804-16805 
161. Hashmi ASK, Grundl L (2005) Gold catalysis: five new bonds by a domino hydroarylation/cycloisomerization. Tetrahedron 61:6231-6236

162. Nagao Y, Tanaka S, Ueki A, Kumazawa M, Goto S, Ooi T, Sano $S$, Shiro M (2004) New ring-expansion reactions of hydroxy propenoyl cyclic compounds under palladium(0)/phosphinecatalyzed conditions. Org Lett 6:2133-2136

163. Hartung RE, Hilmey DG, Paquette LA (2004) Fluoride ionpromoted $a$-ketol rearrangement during unmasking of silylprotected medium-ring dihydroxy ketones. Adv Synth Catal 346:713-716

164. Paquette LA, Hofferberth JE (2003) The $a$-hydroxy ketone (a-ketol) and related rearrangements. Org React 62:477-567

165. Brunner H, Kagan HB, Kreutze G (2003) Asymmetric catalysis. Part 153: metal-catalysed enantioselective $a$-ketol rearrangement. Tetrahedron Asymmetry 14:2177-2187

166. Brunner H, Stohr F (2000) Metal-catalyzed enantioselective $a$-ketol rearrangements. Eur J Org Chem 15:2777-2786

167. Markham JP, Staben ST, Toste FD (2005) Gold(I)-catalyzed ring expansion of cyclopropanols and cyclobutanols. J Am Chem Soc 127:9708-9709

168. Trost BM, Lee DC (1988) Cyclization terminators. Vinylcyclopropanol as a composite functional group. J Am Chem Soc 110:6556-6558

169. Sworin M, Neumann WL (1988) Cyclopentanoid synthesis via directed cationic cyclizations. Efficient generation and rearrangement of the intermediate cyclohexyl cation. J Org Chem 53:4894-4896

170. Sano T, Toda J, Tsuda Y (1984) 2-Azabicyclo[3.2.0]heptane3,4-dione: a novel acid catalyzed skeletal rearrangement of 7-oxy-7-vinyl derivatives to 2-azatricyclo[4.3.0.04,9]nonane3,7-diones. Heterocycles 22:53-58

171. Binder JT, Crone B, Kirsch SF, Liebert C, Menz H (2007) Synthesis of heterocyclic systems by transition-metal-catalyzed cyclization-migration reactions - a diversity-oriented strategy for the construction of spirocyclic $3(2 \mathrm{H})$-furanones and 3-pyrrolones. Eur J Org Chem 10:1636-1647

172. Boumendjel A, Aurones A (2003) Aurones: a subclass of flavones with promising biological potential. Curr Med Chem 10:2621-2630

173. Brooks CJ, Watson DG (1985) Phytoalexins. Nat Prod Rep 2:427-459

174. Morimoto M, Fukumoto H, Nozoe T, Hagiwara A, Komai K (2007) Synthesis and insect antifeedant activity of aurones against Spodoptera lituralarvae. J Agric Food Chem 55:700-705

175. Okombi S, Rival D, Bonnet S, Mariotte A-M, Perrier E, Boumendjel A (2006) Discovery of benzylidenebenzofuran-3(2H)-one (aurones) as inhibitors of tyrosinase derived from human melanocytes. J Med Chem 49:329-333

176. Venkateswarlu S, Panchagnula GK, Subbaraju GV (2004) Synthesis and antioxidative activity of $3^{\prime}, 4^{\prime}, 6,7$-tetrahydroxyaurone, a metabolite of Bidens frondosa. Biosci Biotechnol Biochem 68:2183-2185

177. Auf'mkolk M, Koerhle J, Hesch RD, Cody V (1986) Inhibition of rat liver iodothyronine deiodinase. Interaction of aurones with the iodothyronine ligand binding site. Biol Chem 261:11623-11630

178. Donnelly JA, Fox MJ, Sharma TC (1979) $a$-Halogenoketones-XI. Tetrahedron 35:875-879

179. Bose G, Mondal E, Khan AT, Bordoloi MJ (2001) An environmentally benign synthesis of aurones and flavones from 2'-acetoxychalcones using $n$-tetrabutylammonium tribromide. Tetrahedron Lett 42:8907-8909

180. Levai A, Tokes AL (1982) Synthesis of aurones by the oxidative rearrangement of 2'-hydroxychalcones with thallium (III) nitrate. Synth Commun 12:701-707
181. Imafuku K, Honda M, McOmie JFW (1987) Cyclodehydrogenation of 2'-hydroxychalcones with DDQ: a simple route for flavones and aurones. Synthesis 2:199-201

182. Sekizaki H (1988) Synthesis of 2-benzylidene-3(2H)-benzofuran-3-ones (aurones) by oxidation of 2'-hydroxychalcones with mercury(II) acetate. Bull Chem Soc Jpn 61:1407-1409

183. Thakkar K, Cushman MA (1995) A novel oxidative cyclization of 2'-hydroxychalcones to 4,5-dialkoxyaurones by thallium(III) nitrate. J Org Chem 60:6499-6510

184. An Z-W, Catellani M, Chiusoli GP (1990) Palladium-catalyzed synthesis of aurone from salicyloyl chloride and phenylacetylene. J Organomet Chem 397:371-373

185. Harkat H, Blanc A, Weibel J-M, Pale P (2008) Versatile and expeditious synthesis of aurones via Aul-catalyzed cyclization. J Org Chem 73:1620-1623

186. Alcaide B, Almendros P, Alonso JM (2011) Gold-catalyzed cyclizations of alkynol-based compounds: synthesis of natural products and derivatives. Molecules 16:7815-7843

187. Arcadi A, Abbiati G, Rossi E (2011) Tandem imination/annulation of $\gamma$ - and $\delta$-ketoalkynes in the presence of ammonia/ amines. J Organomet Chem 696:87-98

188. Dell'Acqua M, Facoetti D, Abbiati G, Rossi E (2010) Selective base-promoted synthesis of dihydroisobenzofurans by domino addition/annulation reactions of ortho-alkynylbenzaldehydes. Synthesis 41:2367-2378

189. Hashmi ASK, Salathe R, Frey W (2007) Gold-catalyzed cyclization of $N$-alkynyl carbamates. Synlett 11:1763-1766

190. Lim C, Kang J-E, Ji-Eun Lee J-E, Shin S (2007) Gold-catalyzed tandem $\mathrm{C}-\mathrm{C}$ and $\mathrm{C}-\mathrm{O}$ bond formation: a highly diastereoselective formation of cyclohex-4-ene-1,2-diol derivatives. Org Lett 9:3539-3542

191. Robles-Machin R, Adrio J, Carretero JC (2006) Gold-catalyzed synthesis of alkylidene 2-oxazolidinones and 1,3-oxazin2-ones. J Org Chem 71:5023-5026

192. Aponick A, Li C-Y, Palmes JA (2009) Au-catalyzed cyclization of monopropargylic triols: an expedient synthesis of monounsaturated spiroketals. Org Lett 11:121-124

193. Zhang Y, Xue JJ, Xin ZJ, Xie ZX, Li Y (2008) Gold-catalyzed double intramolecular alkyne hydroalkoxylation: synthesis of the bisbenzannulated spiroketal core of rubromycins. Synlett 6:940-944

194. Huang H, Zhou Y, Liu H (2011) Recent advances in the gold-catalyzed additions to $\mathrm{C}-\mathrm{C}$ multiple bonds. Beilstein J Org Chem 7:897-936

195. Wang YH, Zhu LL, Zhang YX, Chen ZL (2010) Diastereoselective $\gamma$-vinyl butyrolactone synthesis via gold catalyzed cyclization of allylic acetate. Chem Commun 46:577-579

196. Seraya E, Slack E, Ariafard A, Yates BF, Hyland CJT (2010) Experimental and theoretical investigation into the goldcatalyzed reactivity of cyclopropenylmethyl acetates. Org Lett 12:4768-4771

197. Liu L-P, Xu B, Mashuta MS, Hammond GB (2008) Synthesis and structural characterization of stable organogold(I) compounds. Evidence for the mechanism of gold-catalyzed cyclizations. J Am Chem Soc 130:17642-17643

198. Liu Y, Qian J, Lou S, Xu Z (2010) Gold(III)-catalyzed tandem reaction of $O$-arylhydroxylamines with 1,3-dicarbonyl compounds: highly selective synthesis of 3-carbonylated benzofuran derivatives. J Org Chem 75:6300-6303

199. Ballini R, Petrini M (2009) Nitroalkanes as key building blocks for the synthesis of heterocyclic derivatives. ARKIVOC 9:195-223

200. Sherry BD, Maus L, Laforteza BN, Toste DF (2006) Gold(I)catalyzed synthesis of dihydropyrans. J Am Chem Soc 128:8132-8133

201. Alcaide B, Almendros P, Carrascosa R, Torres MR (2010) Gold/ acid-co-catalyzed regiodivergent preparation of bridged ketals 
via direct bis-oxycyclization of alkynic acetonides. Adv Synth Catal 352:1277-1283

202. Perron F, Albizati KF (1989) Chemistry of spiroketals. Chem Rev 89:1617-1661

203. Aho JE, Pihko PM, Rissa TK (2005) Nanometric spiroketals in natural products: structures, sources, and synthetic strategies. Chem Rev 105:4406-4440

204. Rama Raju B, Saikia AK (2008) Asymmetric synthesis of naturally ocurring spiroketals. Molecules 13:1942-2038

205. Blunt JW, Copp BR, Hu WP, Munro MHG, Northcote PT, Prinsep MR (2009) Marine natural products. Nat Prod Rep 26:170-244

206. Brimble MA, Bryant CJ (2006) Synthesis of the spiroketalcontaining anti-helicobacter pylori agents. Chem Commun 43:4506-4508

207. Izquierdo-Cubero I, Plaza Lopez-Espinosa MT, Kari N (1994) Synthesis of optically active chalcogran from L-sorbose. Carbohydr Res 261:231-242

208. Antoniotti S, Genin E, Michelet V, Genet J-P (2005) Highly efficient access to strained bicyclic ketals via gold-catalyzed cycloisomerization of bis-homopropargylic diols. J Am Chem Soc 127:9976-9977

209. Liu L-P, Hammond GB (2009) Highly efficient and tunable synthesis of dioxabicyclo[4.2.1] ketals and tetrahydropyrans via gold-catalyzed cycloisomerization of 2-alkynyl-1,5-diols. Org Lett 11:5090-5092

210. Liu B, De Brabander JK (2006) Metal-catalyzed regioselective oxy-functionalization of internal alkynes: an entry into ketones, acetals, and spiroketals. Org Lett 8:4907-4910

211. Hashmi ASK, Buhrle $M$, Wolfe $M$, Rudolph $M$, Wieteck $M$, Rominger F, Frey W (2010) Gold catalysis: tandem reactions of diyne-diols and external nuchleophiles as an easy access to tricyclic cage-like structures. Chem Eur J 16:9846-9854

212. Zhang Y, Xue J, Xin Z, Xie Z, Li Y (2008) Gold-catalyzed double intramolecular alkyne hydroalkoxylation: synthesis of the bisbenzannulated spiroketal core of rubromycins. Synlett 6:0940-0944

213. Brockmann H, Lenk W, Scwantje G, Zeeck A (1966) Robromycins. Tetrahedron Lett 7:3525-3530

214. Goldman ME, Salituro GS, Bowen JA, Williamson JM, Zink L, Scleif WA, Emini EA (1990) Inhibition of human immunodefiency virus-1 reverse transcriptase activity by robromycins: competitive interaction at the template primer site. Mol Pharmacol 38:20-28

215. Trani A, Dallanoce C, Pranzone G, Ripamonti F, Goldstein BP, Cibiatti R (1997) Semisynthetic derivatives of purpuromycin as potential topical agents for vaginal infections. J Med Chem 40:967-971

216. Chino M, Nishikawa K, Umekia M, Hayashi C, Yamazaki T, Tsuchida T, Sawa T, Hamada M, Takeuchi T (1996) Heliquinomycin, a new inhibitor of DNA helicase, produced by streptomyces sp. MJ929-SF2. Taxonomy, production, isolation, physicochemical properties and biological activities. J Antibiot 49:752-757

217. Chen C-X, Liu L, Yang D-P, Wang D, Chen Y-J (2005) Indium trichloride catalyzed synthesis of 2-aryl-3-aminobenzofuran -derivatives by a three-component reaction of phenols, arylglyoxal -monohydrates and para-toluenesulfonamide. Synlett 13:2047-2051

218. Zhao J-L, Liu L, Zhang H-B, Wu Y-C, Wang D, Chen Y-J (2006) Three-component Friedel-Crafts reaction of indoles, glyoxylate, and amine under solvent-free and catalyst-free conditions-synthesis of (3-indolyl)glycine derivatives. Synlett 1:96-100

219. Syamala M (2009) Recent progress in three-component reactions: an update. Org Prep Proced Int 41:1-68
220. Yadav AK, Singh BK, Singh N, Tripathi RP (2007) An elegant and unprecedented approach to 2-methylbenzofurans. Tetrahedron Lett 48:6628-6632

221. Parvatkar PT, Parameswaran PS, Tilve SG (2012) Recent developments in the synthesis of five- and six-membered heterocycles using molecular iodine. Chem Eur J 18:5460-5489

222. Kobayashi K, Shikata K, Fukamachi S, Konishi H (2008) A facile synthesis of 1,3-dihydroisobenzofurans using iodocylization of 2-vinylbenzyl alcohols. Heterocycles 75:599-609

223. Mancuso R, Mehta S, Gabriele B, Salerno G, Jenks WS, Larock RC (2010) A simple and mild synthesis of $1 \mathrm{H}$-isochromenes and (Z)-1-alkylidene-1,3-dihydroisobenzofurans by the iodocyclization of 2-(1-alkynyl)benzylic alcohols. J Org Chem 75:897-901

224. Wang C, Lu J, Mao G, Xi Z (2005) Preparation and electrophilic cyclization of multisubstituted dienamides leading to cyclic iminoethers. J Org Chem 70:5150-5156

225. Aly AA, Brown AB, El-Emary TI, Ewas AMM, Ramadane M (2009) Hydrazinecarbothioamide group in the synthesis of heterocycles. ARKIVOC 1:150-197

226. D'Souza BR, Louie J (2009) Nickel-catalyzed cycloadditive couplings of enynes and isocyanates. Org Lett 11:4168-4171

227. Balaji G, Valiyaveettil S (2009) Synthesis and properties of symmetric and unsymmetric dibenzothienopyrroles. Org Lett 11:3358-3361

228. Mehta S, Larock RC (2010) lodine/palladium approaches to the synthesis of polyheterocyclic compounds. J Org Chem 75:1652-1658

229. Singh FV, Wirth T (2012) Hypervalent iodine mediated oxidative cyclization of $o$-hydroxystilbenes into benzo- and naphthofurans. Synthesis 44:1171-1177

230. Carril M, Correa A, Bolm C (2008) Iron-catalyzed Sonogashira reactions. Angew Chem 120:1-5

231. Lautens M, Klute W, Tam W (1996) Transition metal-mediated cycloaddition reactions. Chem Rev 96:49-92

232. Grigg R, Scott R, Stevenson P (1988) Rhodium-catalyzed $2+2+2$-cycloadditions of acetylenes. J Chem Soc Perkin Trans $16: 1357-1364$

233. Lecker SH, Nguyen NH, Vollhardt KPC (1986) Cobalt-catalyzed one-step assembly of B-ring aromatic steroids from acyclic precursors. J Am Chem Soc 108:856-858

234. Vollhardt KPC (1984) Cobalt-mediated $2+2+2$-cycloadditions-a maturing synthetic strategy. Angew Chem Int Ed 23:539-556

235. Grigg R, Scott R, Stevenson $P(1982)$ Rhodium catalyzed $2+2+2$ cycloadditions of acetylenes. Tetrahedron Lett 23:2691-2692

236. Furstner A, Seidel G (1995) Palladium-catalyzed arylation of polar organometallics mediated by 9-methoxy-9-borabicyclo 3.3.1 nonane-Suzuki reactions of extended scope. Tetrahedron 51:11165-11176

237. Fuerstner A, Nikolakis K (1996) Ethynylation of aryl halides by a modified Suzuki reaction Application to the syntheses of combretastatin A-4, A-5, and lunularic acid. Liebigs Ann Chem 12:2107-2113

238. Nielsen MB, Moonen NNP, Boudon C, Gisselbrecht J-P, Seiler P, Gross M, Diederich F, Nielsen MB, Moonen NNP, Boudon C, Gisselbrecht J-P, Seiler P, Gross M, Diederich F (2001) Tetrathiafulvalene-acetylene scaffolding: new $\pi$-electron systems for advanced materials. Chem Commun 18:1848-1849

239. Mori A, Kondo T, Kato T, Nishihara Y (2001) Palladium-catalyzed cross-coupling polycondensation of bisalkynes with dihaloarenes activated by tetrabutylammonium hydroxide or silver(I) oxide. Chem Lett 30:286-287

240. Bunz UHF (2000) Poly(aryleneethynylene)s: syntheses, properties, structures, and applications. Chem Rev 100:1605-1644 
241. Francke V, Mangel T, Mullen K (1998) Synthesis of alpha, omegadifunctionalized oligo- and poly(p-phenyleneethynylene)s. Macromolecules 31:2447-2453

242. Sun R, Masuda T, Kobayashi T (1997) Visible electroluminescence of polyacetylene derivatives. Synth Met 91:301-303

243. Ziener U, Godt A (1997) Synthesis and characterization of monodisperse oligo(phenyleneethynylene)s. J Org Chem 62:6137-6143

244. Tour JM, Jones L, Pearson DL, Lamba JJS, Burgin TP, Whitesides GM, Allara DL, Parikh AN, Atre SV (1995) Self-assembled monolayers and multilayers of conjugated thiols, alpha, omega-dithiols, and thioacetyl-containing adsorbatesunderstanding attachments between potential molecular wires and gold surfaces. J Am Chem Soc 117:9529-9534

245. Bumm LA, Arnold JJ, Cygan MT, Dunbar TD, Burgin TP, Jones L, Allara DL, Tour JM, Weiss PS (1996) Are single molecular wires conducting? Science 271:1705-1707

246. Moroni M, Lemoigne J, Luzzati S (1994) Rigid-rod conjugated polymers for nonlinear optics. Characterization and linear optical-properties of poly(aryleneethynylene) derivatives. Macromolecules 27:562-571

247. Yus M, Foubelo F, Ferrandez JV (2002) DTBB-catalyzed lithiation of 4-hetero-substituted dibenzothiins. Chem Lett 31:726-727

248. Yus M, Foubelo F, Ferrandez JV (2003) Dibenzothiepins, phthalans and phthalides from 4-heterosubstituted dibenzothiins. Tetrahedron 59:2083-2092

249. Yus M, Foubelo F, Ferrandez JV (2002) Thianthrene as a source of the 1,2-benzene dianion. Tetrahedron Lett 43:7205-7207

250. Yus M (2003) Ring opening of heterocycles by an arenecatalyzed lithiation. Pure Appl Chem 75:1453-1475

251. Choudhury PK, Almena J, Foubelo F, Yus M (1997) New homologation of 2-hydroxy and 2-mercapto benzylic alcohols. Tetrahedron 53:17373-17382

252. Hu Y, Zhang Y, Yang Z, Fathi R (2002) Palladium-catalyzed carbonylative annulation ofo-alkynylphenols: syntheses of 2-substituted-3-aroyl-benzo[b]furans. J Org Chem 67:2365-2368

253. Avarez-Corral MA, Munoz-Dorado M, Rodriguez-Garcia I (2008) Silver-mediated synthesis of heterocycles. Chem Rev 108:3174-3198

254. Zanardi A, Mata JA, Peris E (2009) Domino approach to benzofurans by the sequential sonogashira/hydroalkoxylation couplings catalyzed by new $\mathrm{N}$-heterocyclic-carbene-palladium complexes. Organometallics 28:4335-4339

255. Mata JA, Poyatos M (2011) Recent developments in the applications of palladium complexes bearing $\mathrm{N}$-heterocyclic carbene ligands. Curr Org Chem 15:3309-3324

256. Fancellli D, Fagnola MC, Severino D, Bedeschi A (1997) Solid phase synthesis of 2-substituted benzofurans via the palladium-catalysed heteroannulation of acetylenes. Tetrahedron Lett 38:2311-2314

257. Kabalka GW, Wang L, Pagni RM (2001) Sonogashira coupling and cyclization reactions on alumina: a route to aryl alkynes, 2-substituted-benzo[b]furans and 2-substituted-indoles. Tetrahedron 57:8017-8028

258. Esseveldt BCJ, Delft FL, Smits JMM, Gelder R, Schoemaker HE, Rutjesa FPJT (2004) Transition metal-catalyzed synthesis of novel biologically relevant tryptophan analogues. Adv Synth Catal 346:823-834

259. Dai W-M, Lai KW (2002) Chemistry of aminophenols. Part 3: first synthesis of nitrobenzo[b]furans via a coupling-cyclization approach. Tetrahedron Lett 43:9377-9380

260. Wyatt PG, Allen MJ, Chilcott J, Foster A, Livermore DG, Mordaunt JE, Scicinski J, Woollard PM (2002) Identification of potent and selective oxytocin antagonists. Part 1: indole and benzofuran derivatives. Bioorg Med Chem Lett 12:1399-1404
261. Inoue M, Carson MW, Frontier AJ, Danishefsky SJ (2001) Total synthesis and determination of the absolute configuration of frondosin. J Am Chem Soc 123:1878-1889

262. Hosokawa T, Yamashita S, Murahashi S-I, Sonoda A (1976) Regrioselectivity of palladium(II)-induced intramolecular cyclization of 2-(3-methyl-2-butenyl)phenol. Bull Chem Soc Jpn 49:3662-3665

263. Beccalli EM, Broggini G, Martinelli M, Sottocornola S (2007) C-C, $\mathrm{C}-\mathrm{O}, \mathrm{C}-\mathrm{N}$ Bond formation on $\mathrm{sp}^{2}$ carbon by $\mathrm{Pd}(\mathrm{II})$-catalyzed reactions involving oxidant agents. Chem Rev 107:5318-5365

264. Arcadi A, Cacchi S, Di Giuseppe S, Fabrizi G, Marinelli F (2002) New efficient approaches to functionalized 2-substituted furopyridines. Synlett 3:453-457

265. Arcadi A, Marinelli F, Cacchi S (1986) Palladium-catalyzed reaction of 2-hydroxyaryl and hydroxyheteroaryl halides with 1-alkynes: an improved route to the benzo[b]furan ring system. Synthesis 9:749-751

266. Aquila BM (1997) A new synthesis of 8-methylpsoralen utilizing a palladium-copper catalyzed reaction to generate the furan ring and thus allowing for the generation of novel analogs in the 5'-position. Tetrahedron Lett 38:2795-2798

267. Kobiyashi K, Uneda T, Kawakita M, Morikawa O, Kobishi H (1997) One-pot synthesis of naphtho[2,3-b]furan-4,9-diones by sequential coupling/ring closure reactions. Tetrahedron Lett 38:837-840

268. Kundu NG, Pal M, Mahanty JS, De M (1997) Palladium-catalysed heteroannulation with acetylenic compounds: synthesis of benzofurans. J Chem Soc Perkin Trans 19:2815-2820

269. Bhat AS, Whetstone JL, Brueggemeier RW (1999) Novel synthetic routes suitable for constructing benzopyrone combinatorial libraries. Tetrahedron Lett 40:2469-2472

270. Abbiati G, Arcadi A, Beccalli E, Rossi E (2003) Novel intramolecular cyclization of $\mathrm{N}$-alkynyl heterocycles containing proximate nucleophiles. Tetrahedron Lett 44:5331-5334

271. Wei L-L, Wei L-M, Pan W-B, Wu M-J (2004) Palladium-catalyzed esterification-hydroarylation reactions of 2-alkynylbenzaldehydes with aryl iodides in methanol. Synlett 9:1497-1502

272. Patil NT, Yamamoto Y (2004) Synthesis of cyclic alkenyl ethers via intramolecular cyclization of $O$-alkynylbenzaldehydes. Importance of combination between Cul catalyst and DMF. J Org Chem 69:5139-5142

273. Mondal S, Nogami T, Asao N, Yamamoto Y (2003) Synthesis of novel antitumor agent 1-methoxy-5,10-dioxo-5,10-dihydro$1 \mathrm{H}$-benzo[ $\mathrm{g}]$ isochromene carboxylic acid (3-dimethylylaminopropyl)amide with a dual role Pd(II) catalyst. J Org Chem 68:9496-9498

274. Liang Y, Tao L-M, Zhang Y-H, Li J-H (2008) Palladium-catalyzed cross-coupling reactions of 1,2-diiodoalkenes with terminal alkynes: selective synthesis of unsymmetrical buta-1,3-diynes and 2-ethynylbenzofurans. Synthesis 24:3988-3994

275. Hosokawa T, Maeda K, Koga K, Moritani I (1973) One step synthesis of 2-substituted benzofuran derivatives with dichlorobis(benzonitrile)palladium. Tetrahedron Lett 14:739-740

276. Hosokawa T, Shimo N, Maeda K, Sonoda A, Murahashi S-I (1976) Palladium-induced pyridine synthesis from unsaturated ketoximes. Tetrahedron Lett 17:383-386

277. Hegedus LS, Allen GF, Waterman EL (1976) Palladium assisted intramolecular amination of olefins. A new synthesis of indoles. J Am Chem Soc 98:2674-2676

278. Hosokawa T, Ohkata H, Moritani I (1975) Intramolecular oxypalladation. Cyclization reaction of 2-allylphenols with palladium salts. Bull Chem Soc Jpn 48:1533-1536

279. Kundu NG, Pal M, Nandi B (1998) Palladium-catalysed heteroannulation with terminal alkynes: synthesis of phthalides. J Chem Soc Perkin Trans 1:561-568 
280. Ye T, Garcia CF, McKervey MA (1995) Chemoselectivity and stereoselectivity of cyclisation of $a$-diazocarbonyls leading to oxygen and sulfur heterocycles catalysed by chiral rhodium and copper catalysts. J Chem Soc Perkin Trans 1 11:1373-1379

281. Kido F, Yamaji K, Sinha SC, Yoshikoshi A, Kato M (1994) Steric control based on alkyl substituents in the $[2,3]$ sigmatropic rearrangement of nine-membered allylsulfonium ylides. A new entry to the stereoselective synthesis of elemane-type sesquiterpenoids. J Chem Soc Chem Commun 7:789-790

282. Kido F, Yamaji K, Sinha SC, Abiko T, Kato M (1995) Carbocyclic construction by the $[2,3]$ sigmatropic rearrangement of cyclic sulfonium ylides. A new entry for the stereoselective synthesis of substituted cyclohexanones. Tetrahedron 51:7697-7714

283. Simonneaux G, Galardon E, Paul-Roth C, Gulea M, Masson S (2001) Ruthenium-porphyrin-catalyzed carbenoid addition to allylic compounds: application to [2,3]-sigmatropic rearrangements of ylides. J Orgmet Chem 617-618:360-363

284. Zhou C-Y, Yu W-Y, Chan PWH, Che C-M (2004) Ruthenium porphyrin catalyzed tandem sulfonium/ammonium ylide formation and [2,3]-sigmatropic rearrangement. A concise synthesis of ( \pm )-platynecine. J Org Chem 69:7072-7082

285. Carter DS, Van Vranken DL (2000) Iron-catalyzed Doyle-Kirmse reaction of allyl sulfides with (trimethylsilyl)diazomethane. Org Lett 2:1303-1305

286. Carter DS, Van Vranken DL (1999) Metal-catalyzed ylide formation and $[2,3]$ sigmatropic rearrangement of allyl sulfides with trimethylsilyldiazomethane. Tetrahedron Lett 40:1617-1620

287. Aggarwal VK, Ferrara M, Hainz R, Spey SE (1999) [2,3]-Sigmatropic rearrangement of allylic sulfur ylides derived from trimethylsilyldiazomethane (TMSD). Tetrahedron Lett 40:8923-8927

288. Kirmse W, Kapps M (1968) Reaktionen des Diazomethans mit Diallylsulfid und Allyläthern unter Kupfersalz-Katalyse. Chem Ber 101:994-1003

289. Doyle MP, Griffin JH, Chinn MS, van Leusen D (1984) Rearrangements of ylides generated from reactions of diazo compounds with allyl acetals and thioketals by catalytic methods. Heteroatom acceleration of the [2,3]-sigmatropic rearrangement. J Org Chem 49:1917-1925

290. Reggelin M (2007) [2,3]-Sigmatropicrearrangements of allylic sulfur compounds. In: Schaumann E (ed) Sulfur-mediated rearrangements II, topics in current chemistry, vol 275. Springer, Berlin, pp 1-65

291. Kato Y, Miki K, Nishino F, Ohe K, Uemura S (2003) Doyle-Kirmse reaction of allylic sulfides with diazoalkane-free (2-furyl)carbenoid transfer. Org Lett 5:2619-2621

292. Davies PW (2010) Alkynes as "masked" ylides under noblemetal catalysis. Pure Appl Chem 82:1537-1544

293. Davies HML, Grazini MVA, Aouad E (2001) Asymmetric intramolecular $\mathrm{C}-\mathrm{H}$ insertions of aryldiazoacetates. Org Lett 3:1475-1477

294. Miki K, Washitake Y, Ohe K, Uemura S (2004) Polyaddition and polycondensation reactions of (2-furyl)carbenoid as stepgrowth polymerization strategies: synthesis of furylcyclopropane- and furfurylidene-containing polymers. Angew Chem Int Ed 43:1857-1860

295. Cheng G, Mirafzal GA, Woo LK (2003) Iron porphyrin-catalyzed olefination of carbonyl compounds with ethyl diazoacetate. Organometallics 22:1468-1474

296. Aggarwal VK, Fulton JR, Sheldon CG, de Vicente J (2003) Generation of phosphoranes derived from phosphites. A new class of phosphorus ylides leading to high E-selectivity with semi-stabilizing groups in Wittig olefinations. J Am Chem Soc 125:6034-6035
297. Hodgson DM, Pierard FYTM, Stupple PA (2001) Catalytic enantioselective rearrangements and cycloadditions involving ylides from diazo compounds. Chem Soc Rev 30:50-61

298. McCarthy N, McKervey MA, Ye T, McCann M, Murphy E, Doyle MP (1992) New rhodium(II) phosphate catalyst for diazocarbonyl reactions including asymmetric synthesis. Tetrahedron Lett 33:5983-5986

299. Ferris L, Haigh D, Moody CJ (1996) New chiral rhodium(II) carboxylates and their use as catalysts in carbenoid transformations. Tetrahedron Lett 37:107-110

300. Pierson N, Fernandez-Garcia C, McKervey MA (1997) Catalytic asymmetric oxonium ylide-[2,3] sigmatropic rearrangement with diazocarbonyl compounds: first use of C2-symmetry in $\mathrm{Rh}$ (II) carboxylates. Tetrahedron Lett 38:4705-4708

301. Calter MA, Sugathapala PM (1998) Orthoester condensation/ $\mathrm{CO}$ insertion reaction sequence for the preparation of tetrahydrofurans. Tetrahedron Lett 39:8813-8816

302. Hodgson DM, Petroliagi M (2001) Rh(II)-binaphthol phosphate catalysts in the enantioselective intramolecular oxonium ylide formation-[3,2]sigmatropic rearrangement of $\alpha$-diazo- $\beta$ ketoesters. Tetrahedron Asymmetry 12:877-881

303. Kitagaki S, Yanamoto $Y$, Tsutsui $H$, Anada M, Nakajima M, Hashimoto S (2001) Enantioselective [2,3]-sigmatropic and [1,2]-Stevens rearrangements via intramolecular formation of allylic oxonium ylides catalyzed by chiral dirhodium(II) carboxylates. Tetrahedron Lett 42:6361-6364

304. Doyle MP, Shanklin MS (1994) Highly regioselective and stereoselective silylformylation of alkynes under mild conditions promoted by dirhodium(II) perfluorobutyrate. Organometallics 13:1081-1088

305. Doyle MP, van Oeveren A, Westrum LJ, Protopopova MN, Clayton JTW (1991) Asymmetric synthesis of lactones with high enantioselectivity by intramolecular carbon-hydrogen insertion reactions of alkyl diazoacetates catalyzed by chiral rhodium(II) carboxamides. J Am Chem Soc 113:8982-8984

306. McKervey MA, Ye T (1992) Asymmetric synthesis of substituted chromanones via $\mathrm{C}-\mathrm{H}$ insertion reactions of a-diazoketones catalysed by homochiral rhodium(II) carboxylates. J Chem Soc Chem Commun 11:823-824

307. Doyle MP, Protopopava MN, Winchester WR, Daniel KL (1992) Enantiocontrol and regiocontrol in lactam syntheses by intramolecular carbon-hydrogen insertion reactions of diazoacetamides catalyzed by chiral rhodium(II) carboxamides. Tetrahedron Lett 33:7819-7822

308. Hashimoto S, Watanabe N, Sato T, Shiro M, Ikegami S (1993) Enhancement of enantioselectivity in intramolecular $\mathrm{C}-\mathrm{H}$ insertion reactions of $\alpha$-diazo $\beta$-keto esters catalyzed by chiral dirhodium(II) carboxylates. Tetrahedron Lett 34:5109-5112

309. Ojima I, Tzamarioudaki M, Li Z, Donovan RJ (1996) Transition metal-catalyzed carbocyclizations in organic synthesis. Chem Rev 96:635-662

310. Lee SI, Park SY, Park JH, Jung IG, Choi SY, Chung YK, Lee BY (2006) Rhodium $\mathrm{N}$-heterocyclic carbene-catalyzed [4+2] and [5+2] cycloaddition reactions. J Org Chem 71:91-96

311. McDonald FE, Smolentsev V (2002) Synthesis of monodisperse oligo- $p$-phenylenes via rhodium-catalyzed alkyne cyclotrimerization. Org Lett 4:745-748

312. Kotha S, Brahmachary E, Lahiri K (2005) Transition metal catalyzed $[2+2+2]$ cycloaddition and application in organic synthesis. Eur J Org Chem 22:4741-4767

313. Witulski B, Zimmermann A (2002) Synthesis of chiral 3-substituted phthalides via rhodium(I)-catalyzed crossed alkyne cyclotrimerisation. Synlett 11:1855-1859

314. Moody CJ, Doyle KJ, Elliott MC, Mowlem TJ (1994) Synthesis of heterocyclic natural products: model studies towards diazonamide A. Pure Appl Chem 66:2107-2110 
315. Muller P, Allenbach YF, Bernardinelli G (2003) On the enantioselectivity of transition metal-catalyzed 1,3-cycloadditions of 2-diazocyclohexane-1,3-diones. Helv Chim Acta 86:3164-3178

316. Muller P, Granicher C, Klaerner F-G, Breitkopf V (1995) Metallocarbene intermediates in rhodium(II)-catalyzed rearrangements of ethyl 2-butylcycloprop-1-ene-1-carboxylate. Gazz Chim Ital 125:459-463

317. Rubin M, Ryabchuk PG (2012) Rearrangements of cyclopropenes into five-membered aromatic heterocycles: mechanistic aspect. Chem Heterocycl Compd 48:126-138

318. Rubin M, Rubina M, Gevorgyan V (2007) Transition metal chemistry of cyclopropenes and cyclopropanes. Chem Rev 107:3117-3179

319. Du X, Armstrong RW (1997) Synthesis of benzofuran derivatives on solid support via $\mathrm{Sml}_{2}$-mediated radical cyclization. J Org Chem 62:5678-5679

320. Mirizzi D, Pulici M (2011) From polymer to small organic molecules: a tight relationship between radical chemistry and solid-phase organic synthesis. Molecules 16:3252-3314

321. Blanc A, Tenbrink K, Weibel J-M, Pale P (2009) Silver(I)-catalyzed cascade: direct access to furans from alkynyloxiranes. J Org Chem 74:4360-4363

322. Das A, Sohel SMA, Liu R-S (2010) Carbo- and heterocyclization of oxygen- and nitrogen-containing electrophiles by platinum, gold, silver and copper species. Org Biomol Chem 8:960-979

323. Bellina F, Ciucci D, Vergamini P, Rossi R (2000) Regioselective synthesis of natural and unnatural (Z)-3-(1-alkylidene)phthalides and 3-substituted isocoumarins starting from methyl 2-hydroxybenzoates. Tetrahedron 56:2533-2545

324. Weibel J-M, Blanc A, Pale P (2008) Ag-mediated reactions: coupling and heterocyclization reactions. Chem Rev 108:3149-3173

325. Kirsch G, Hesse S, Comel A (2004) Synthesis of five- and sixmembered heterocycles through palladium-catalyzed reactions. Curr Org Synth 1:47-63

326. Huang $P Q$, Zhou WS (1991) Efficient syntheses of a new chiral diene and a new bridgehead enone for a Diels-Alder approach to kaura-9(11)-16-dien-19-oic acid. Tetrahedron Asymmetry 2:875-878

327. Westermann B, Dubberke S (1997) Synthesis of bicyclic homochiral dienes by allylic rearrangement of cyclohexenols-suitable building blocks for the synthesis of nagilactones. Liebigs Ann 2:375-380

328. Jong TT, Leu S-J (1990) Intramolecular cyclisation catalysed by silver(I) ion; a convenient synthesis of aurones. J Chem Soc Perkin Trans 1 2:423-424

329. Ito Y, Kato R, Hamashima K, Kataoka Y, Oe Y, Ohta T, Furukawa I (2007) Intramolecular cyclization of phenol derivatives with CC double bond in a side chain. J Organomet Chem 692:691-697

330. Sunderrajan S, Freeman BD, Hall CK (1999) Fourier transform infrared spectroscopic characterization of olefin complexation by silver salts in solution. Ind Eng Chem Res 38:4051-4059

331. Yang CG, Reich NW, Shi Z, He C (2005) Intramolecular additions of alcohols and carboxylic acids to inert olefins catalyzed by silver(I) triflate. Org Lett 7:4553-4556
332. Rossi R, Bellina F, Bechini C, Mannina L, Vergamini P (1998) Studies on the transition metal-catalyzed synthesis of variously substituted (E)-3-[1-(aryl)methylidene]- and (E)-3-(1-alkylidene)3H-furan-2-ones. Tetrahedron 54:135-156

333. Ogawa Y, Maruno M, Wakamatsu T (1995) Efficient synthesis of naturally occurring ligustilide. Synlett 8:871-872

334. Rossi R, Bellina F, Biagetti M, Mannina L (1998) Stereocontrolled synthesis of lissoclinolide by sequential transition metal-catalyzed lactonization/cross-coupling reactions. Tetrahedron Lett 39:7799-7802

335. Xu C, Negishi E (1999) A highly efficient and selective synthesis of lissoclinolide featuring hydrogen transfer hydrozirconation, trans-selective Pd-catalyzed cross coupling of alkenylzirconiums with 1,1-dibromoalkenes and Ag-catalyzed lactonization providing (Z)- $\gamma$-alkylidenebutenolides. Tetrahedron Lett 40:431-434

336. Negishi E, Kotora M (1997) Regio- and stereoselective synthesis of $\gamma$-alkylidenebutenolides and related compounds. Tetrahedron 53:6707-6738

337. Ogawa Y, Maruno M, Wakamatsu T (1995) Silver catalyzed cyclization of alkynoic acids: efficient synthesis of 3 -alkylidenephthalides, $\gamma$-alkylidenebutenolides, and $\gamma$-alkylidenebutyrolactones. Heterocycles 41:2587-2599

338. Anastasia L, Xu C, Negishi E (2002) Catalytic and selective conversion of (Z)-2-en-4-ynoic acids to either $2 \mathrm{H}$-pyran-2-ones in the presence of $\mathrm{ZnBr}_{2}$ or ( $\left.\mathrm{Z}\right)$-5-alkylidenefuran-2(5H)-ones in the presence of $\mathrm{Ag}_{2} \mathrm{CO}_{3}$. Tetrahedron Lett 43:5673-5676

339. Marshall JA, Pinney KG (1993) Stereoselective synthesis of 2,5-dihydrofurans by sequential $\mathrm{S}_{\mathrm{N}} 2^{\prime}$ cleavage of alkynyloxiranes and silver(I)-catalyzed cyclization of the allenylcarbinol products. J Org Chem 58:7180-7184

340. Marshall JA, Wang XJ (1990) [2,3]-Wittig rearrangement of nonracemic (propargyloxy)acetic acids and esters. Synthesis of optically active 2,5-dihydrofurans. J Org Chem 55:2995-2996

341. Marshall JA, Yu RH, Perkins JF (1995) Diastereo- and enantioselective synthesis of allenylcarbinols through SE2' addition of transient nonracemic propargylic stannanes to aldehydes. J Org Chem 60:5550-5555

342. Lee YR, Kim NS, Kim BS (1997) Facile strategy to 3-acylfurans by silver(I)/celite-mediated cycloaddition of 1,3-dicarbonyl compounds to vinyl sulfides. First total synthesis of $a$-clausenan. Tetrahedron Lett 38:5671-5674

343. Breton GW, Shugart JH, Hughey CA, Conrad BP, Perala SM (2001) Use of cyclic allylic bromides in the zinc-mediated aqueous Barbier-Grignard reaction. Molecules 6:655-662

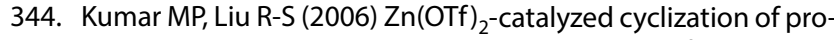
paryl alcohols with anilines, phenols, and amides for synthesis of indoles, benzofurans, and oxazoles through different annulation mechanisms. J Org Chem 71:4951-4955

Publisher's Note Springer Nature remains neutral with regard to jurisdictional claims in published maps and institutional affiliations. 